IZA DP No. 9579

The Individual Perception of Wage Inequality:

A Measurement Framework and Some Empirical Evidence

Andreas Kuhn

December 2015 


\title{
The Individual Perception of Wage Inequality: A Measurement Framework and Some Empirical Evidence
}

\author{
Andreas Kuhn \\ Swiss Federal Institute for Vocational Education and Training, \\ University of Lucerne and IZA
}

\section{Discussion Paper No. 9579 December 2015}

\author{
IZA \\ P.O. Box 7240 \\ 53072 Bonn \\ Germany \\ Phone: $+49-228-3894-0$ \\ Fax: +49-228-3894-180 \\ E-mail: iza@iza.org
}

Any opinions expressed here are those of the author(s) and not those of IZA. Research published in this series may include views on policy, but the institute itself takes no institutional policy positions. The IZA research network is committed to the IZA Guiding Principles of Research Integrity.

The Institute for the Study of Labor (IZA) in Bonn is a local and virtual international research center and a place of communication between science, politics and business. IZA is an independent nonprofit organization supported by Deutsche Post Foundation. The center is associated with the University of Bonn and offers a stimulating research environment through its international network, workshops and conferences, data service, project support, research visits and doctoral program. IZA engages in (i) original and internationally competitive research in all fields of labor economics, (ii) development of policy concepts, and (iii) dissemination of research results and concepts to the interested public.

IZA Discussion Papers often represent preliminary work and are circulated to encourage discussion. Citation of such a paper should account for its provisional character. A revised version may be available directly from the author. 


\begin{abstract}
The Individual Perception of Wage Inequality: A Measurement Framework and Some Empirical Evidence*

This paper presents a simple conceptual framework specifically tailored to measure individual perceptions of wage inequality. Using internationally comparable survey data, the empirical part of the paper documents that there is huge variation in inequality perceptions both across and within countries as well as survey-years. Focusing on the association between aggregate-level inequality measures and individuals' subjective perception of wage inequality, it turns out that there is both a high correlation between the two measures as well as a considerable amount of misperception of the prevailing level of inequality. The final part of the analysis shows that subjective inequality perceptions appear to be more important, in a statistical sense, in explaining variation in individual-level attitudes towards social inequality than objective measures of inequality. This underlines the conceptual and practical importance of distinguishing between subjective perceptions of inequality and the true level of inequality.
\end{abstract}

JEL Classification: D31, D63, J31

Keywords: inequality perceptions, inequality, attitudes towards social inequality, (mis-)perceptions of socio-economic phenomena

Corresponding author:

Andreas Kuhn

Swiss Federal Institute for Vocational Education and Training

Kirchlindachstrasse 79

3052 Zollikofen

Switzerland

E-mail: andreas.kuhn@ehb-schweiz.ch

\footnotetext{
${ }^{*}$ I thank Beatrice Brunner for many helpful comments and suggestions and Sally Gschwend-Fisher for proofreading the manuscript.
} 


\section{Introduction}

In a wide variety of contexts, individuals' subjective perception of socio-economic phenomena might differ substantively from the "true" state - or, rather, the corresponding scientific representation - of the given object of interest. ${ }^{1}$ From an economic point of view, probably one of the most interesting, and certainly one of the most relevant examples where reality and individuals' subjective perceptions may diverge from each other is the distribution of economic resources because a high level of inequality is expected to feed back into the political sphere by influencing individuals' attitudes towards social inequality, such as their beliefs about the determinants of individual pay. Individuals' attitudes towards social inequality, in turn, likely influence their attitudes towards marginal tax rates and other policy parameters which are ultimately crucial in determining the effective amount of (re-)distribution of economic resources (e.g. Alesina and Angeletos, 2005; Bénabou and Tirole, 2006). ${ }^{2}$

However, given the computational complexity and the large amount of information necessarily involved in obtaining a well-informed perception of the prevailing level of inequality in an individual's country of residence, it is likely that many, if not most, individuals have biased perceptions about the truly prevailing level of inequality. Indeed, the existing empirical evidence, primarily based on survey data, has consistently shown that there is huge variation in individuals' perceptions of occupational wages (e.g. Kelley and Evans, 1993; Kluegel and Smith, 1981; Osberg and Smeeding, 2006) and, consequently, in their overall assessment of the extent of wage inequality as well (e.g. Cruces et al., 2013; Engelhardt and Wagener, 2014; Gimpelson and Treisman, 2015; Kuhn, 2011; Niehues, 2014; Schneider, 2012). It appears more difficult to assess, however, whether people tend to under- or overestimate the true level of inequality in part because the measured level of misperception appears to depend on the specific measurement framework used. For example, while Norton and Ariely (2011) find that Americans

\footnotetext{
${ }^{1}$ Such as the perception of tax rates (Gemmell et al., 2004), the perception of corruption (Olken, 2009), or individuals' self-assessment of how their own wellbeing would change as a result of various life events (Odermatt and Stutzer, 2015). One persistent and well-known finding relates to individuals' (mis-)perception of probabilistic events (e.g. Dohmen et al., 2009).

${ }^{2}$ Consistent with this line of reasoning, evidence is accumulating on behavioral and attitudinal spillovers from inequality from a diversity of contexts and based on either experimental (e.g. Card et al., 2012; Clark et al., 2010; Kuziemko et al., 2015) or non-experimental data (e.g. Clark et al., 2010; Cornelissen et al., 2011; Dube et al., 2015; Kuhn, 2015; Pfeifer, 2015). Moreover, a related literature, focusing on the effect of inequality on subjective measures of satisfaction or happiness, generally finds that higher inequality is associated with less satisfaction and/or lower happiness (e.g. Senik, 2005; Verme, 2011).
} 
grossly underestimate the inequality in the distribution of wealth, both Eriksson and Simpson (2012) and Chambers et al. (2014) conclude that Americans tend to overestimate the existing extent of wage inequality. Clearly, the two results need not necessarily contradict each other, but part of the difference appears to be driven by the choice of the measurement framework (Eriksson and Simpson, 2012).

Either way, however, potential discrepancies between the true level of inequality and individuals' subjective perceptions of inequality are relevant for the political-economic implications of inequality because it appears obvious, prima facie, to assume that it is individual-level perceptions of inequality, rather than the objective level of inequality, which ultimately shape individuals' attitudes towards inequality (e.g. Gimpelson and Treisman, 2015; Kuhn, 2011, 2015; Schneider, 2012). From an empirical point of view, then, one of the key challenges in approaching these questions empirically is the need for an empirical approximation to individual-level perceptions of wage inequality because, in contrast to the measurement of the objective level of wage inequality, there is no readily available measurement framework at hand.

In this paper, I present a simple yet intuitive measurement framework suitable for constructing an empirical approximation of individual-level perceptions of wage inequality (as I will discuss in more detail below, as a byproduct, the framework also yields estimates of individuals' perceptions of the overall wage level prevailing in their country of residence). ${ }^{3}$ The intuitive nature of the framework derives from the fact that it is essentially based on a simple analogy with the measurement of the objective level of wage inequality using the well-known Gini coefficient, presumably one of the most often used measures of inequality in conventional applications (i.e. the measurement of inequality based on objective-level data on wages). The kind of data needed to apply the framework in practice are already available in several existing surveys, as discussed in more detail in section 2 below; including the necessary items in future surveys on the subject would be straightforward.

In the second, empirical part of the paper, I apply the measurement framework using inter-

\footnotetext{
${ }^{3}$ The same data were used with a similar purpose by several previous studies (e.g. Jasso, 1999; Niehues, 2014; Osberg and Smeeding, 2006), but all of these studies used different frameworks to measure individuals' inequality perceptions. The key feature and main advantage (mainly in terms of interpretation) of the framework proposed in this paper is that it is constructed analogously to the conventional Gini coefficient, as discussed in more detail in section 3 below. Moreover, considering the results from Eriksson and Simpson (2012) and Chambers et al. (2014) on the relevance of the measurement framework, the fact that the framework proposed here does not rely on individual estimates of relative frequencies may be another advantage.
} 
nationally comparable survey data from the International Social Survey Programme, covering about 65,000 individuals from up to 23 different countries and up to 4 different points in time, with the first surveys administered in 1987 and the most recent ones in 2009. The relatively large number of 61 distinct aggregate cells (i.e. cells defined over country $\times$ survey-year) offers the rare opportunity to study how inequality perceptions are associated with the objectively measured degree of inequality in a country, an issue which has, mainly due to data limitations, not yet received much attention in the literature - despite its obvious relevance from a political-economic perspective.

The empirical analysis of individual-level inequality perceptions, constructed according to the conceptual framework laid out in this paper, yields several interesting findings. First, and consistent with previous evidence on the subject, I find that there is huge variation in individuallevel inequality perceptions, both within and across countries as well as survey-years. I also find that there is a strong correlation of individual-level inequality perceptions within aggregate cells; that is, individuals observed in the same country and the same survey-year tend to have more similar perceptions of wage inequality than randomly picked respondents, suggesting that respondents from the same country actually tend to form perceptions towards a common, though not necessarily the correct, economic phenomenon (i.e. the degree of inequality in their respective country of residence). The empirical analysis further shows that there is a substantial positive correlation between the objective level of inequality and mean inequality perceptions in a given country and year, but also that people tend to overestimate the prevailing level of inequality, consistent with evidence from some previous studies (e.g. Chambers et al., 2014; Eriksson and Simpson, 2012; Gimpelson and Treisman, 2015). The final part of the empirical analysis focuses on the question of whether the distinction between inequality and inequality perceptions has any bearing for the analysis of the potential spillovers on individuals' attitudes towards and beliefs about inequality. In this regard, regressions including both inequality perceptions and aggregate-level inequality measures show, for different attitudinal measures, that inequality perceptions are more important in predicting attitudes towards inequality than aggregate-level measures of the objective level of inequality. Moreover, I also find that using aggregate-level measures in place of inequality perceptions may even yield qualitatively wrong conclusions. 
The remainder of this paper proceeds as follows. The following section discusses the data used in the empirical part of the paper. Section 3 then sketches the conceptual framework used to measure individual-level inequality perceptions. Section 4 presents some basic descriptive evidence related to this measure, documenting systematic variation in inequality perceptions both across and within regions and over time. The main part of the paper is presented in section 5, which focuses on the association between the objective level of inequality and subjective, individual-level perceptions of wage inequality. This section also provides a direct quantification of inequality perceptions. In a complementary analysis, section 6 studies the predictive power of both aggregate-level inequality measures and individual-level inequality perceptions when both are used simultaneously to explain variation in individuals' attitudes to social inequality. Section 7 concludes.

\section{Data}

\subsection{Survey Data}

The primary data source for the empirical analysis is the "Social Inequality" cumulation, a data file that combines several surveys on the causes and consequences of social inequality, administered and made available by the International Social Survey Programme (ISSP). The data combine four individual rounds of a survey designed to focus specifically on individuals' perceptions of the causes and consequences of social inequality. The four surveys were administered in 1987, 1992, 1999, and 2009, respectively (ISSP Research Group, 2014a,b). ${ }^{4}$

The data from the "Social Inequality" cumulation cover a large number of survey items on individuals' attitudes towards social inequality, including, for example, their beliefs about the causes of individual economic success, their satisfaction with their own compensation from work, or their support of redistribution by the state as well as of progressive taxation (cf. Kuhn, 2015). Moreover, the data cover a relatively long period of time and, at least in the more recent waves of the survey, quite a large number of distinct countries from different parts of the world (appendix table A.1 shows the number of individual observations in the analysis sample by

\footnotetext{
${ }^{4}$ The data are available to researchers from the GESIS data archive (www.gesis.org). More information about the ISSP is available from the organization's website (www.issp.org). Note that the cumulation file contains a harmonized list of variables, but that it does not cover all of the countries taking part in the separate waves of the survey.
} 
country and survey-year). They thus provide the unique opportunity to assess the empirical association between subjective inequality perceptions and the objective level of inequality.

\title{
Subjective Wage Estimates for People Working in Specific Occupations
}

As will be discussed in detail in section 3 below, the conceptual framework used to measure individual-level inequality perceptions is essentially based on individuals' subjective wage estimates for people working in different occupations. Specifically, respondents were asked in each round of the survey to give their best estimate of the wages actually paid in different occupations, such a doctor in general practice for example. The exact wording of the question is as follows (see also footnote 6 below):

\begin{abstract}
"We would like to know what you think people in these jobs actually earn. Please write how much you think they actually earn each month (before taxes, but after social security contributions). Many people are not exactly sure about this, but your best guess will be close enough."
\end{abstract}

In some versions of the survey, respondents were asked to estimate wages for up to fifteen different occupations. Somewhat unfortunately, however, only four occupations appear consistently in all four rounds of the survey, namely: (i) "an unskilled worker in a factory", (ii) "a doctor in general practice", (iii) "a cabinet minister in the national government", and (iv) "the chairman of a large national company". For maximal comparability across the different waves of the survey, I will only use individuals' wage estimates referring to these four occupations to construct the empirical approximation of inequality perceptions used in the main part of the empirical analysis (as discussed in detail in section 3 below).

\section{$2.2 \quad$ Aggregate Statistics}

I complement the individual-level survey data from the ISSP with a few aggregate statistics taken from published statistics of the World Bank. ${ }^{5}$ These include, most importantly, the Gini coefficient with respect to the distribution of income, both before and after taxes and transfer

\footnotetext{
${ }^{5}$ These aggregate statistics are all taken from the World Bank's homepage (www.worldbank.org). For those years where the Gini coefficients are not directly available, but where information on both some year prior and some year after the survey-year is available, I use an imputed/interpolated value based on a simple regression of the corresponding Gini on a linear time trend (separately for each country).
} 
payments, as well as a country's per-capita GDP (measured in constant 2005 US dollars), its annual growth rate, its unemployment rate, and its labor force participation rate.

Obviously, the objective measures of aggregate-level inequality are of key interest when focusing on a direct comparison between perceptions of inequality and any objective measure of inequality. It is also obvious that such a comparison can only be meaningful if a relatively large number of aggregate units is available. Fortunately, this is the case for the ISSP cumulation data, which cover a relatively large number of distinct aggregate-level cells (i.e. cells defined at the country $\times$ survey-year level). Due to restrictions related to the availability of some of the additional aggregate-level variables (e.g. the two objective-level Gini coefficients), it is not possible to use the full set of aggregate-cells in most parts of the empirical analysis. Nonetheless, the main analysis below is still based on a comparatively large number of 61 distinct aggregate cells.

It is also worth emphasizing at this point, however, that a direct comparison must be interpreted with sufficient care because the two variables measure distinct phenomena in principle. While individual-level inequality perceptions are explicitly constructed to capture an individual's perception of wage differentials, aggregate-level Gini coefficients relate to the distribution of incomes, not wages. ${ }^{6}$ We should therefore not expect the two measures to be perfectly correlated, even if all individuals had perfect information about the true extent of wage inequality. ${ }^{7}$

\section{Measuring Inequality Perceptions}

In this section, I discuss how to construct subjective measures of inequality perceptions, drawing on a simple conceptual framework initially proposed by and discussed in more detail in Kuhn (2011). ${ }^{8}$ Because the framework basically tries to "mimic" the computation of inequality in the case of objective data on wages, the obvious and most natural starting point for the discussion

\footnotetext{
${ }^{6}$ Moreover, while most respondents were asked to estimate earnings before taxes, respondents in a few realizations of the survey were asked to estimate wages after taxes. This further complicates any simple comparison between the two measures.

${ }^{7}$ As I will discuss in more detail in section 3.3 below, it will also be possible to compare the effective mean wage in a given country and year, approximated by the corresponding per-capita GDP, and mean subjective perceptions of a country's overall wage.

${ }^{8}$ Kuhn (2013) provides kind of a validity check of the framework, showing that the framework is able to capture plausible differentials in inequality perceptions between (former) East and West Germany; consistent with evidence from other, independent sources of data (Alesina and Fuchs-Schündeln, 2007). The difference in inequality perceptions between former East and West Germany also shows up in this analysis (see appendix table A.2).
} 
of the measurement of subjective inequality perceptions is the measurement of objective wage inequality.

\subsection{Measuring Aggregate-Level Inequality Using Objective Wages}

Without doubt, one of the most routinely used and best known inequality measures is the Gini coefficient. While the computation of the Gini coefficient in practice is usually based on individual-level data, it is well-known that it is also possible to work with group-level data on wages (e.g. Gastwirth and Glauberman, 1976; Kakwani and Podder, 1973). In fact, in the simplest case, observing wage information for only two distinct groups of individuals is sufficient for approximating the underlying inequality of individual wages. ${ }^{9}$ I will focus on this special case in what follows because it most easily translates to the case of subjective wage data (see section 3.2 below).

Formally, assume that there are only two, mutually exclusive and exhaustive, groups of wage earners (referred to as bottom and top group, respectively, in what follows) and that we observe the following statistical information describing the distribution of wages across these two groups of individuals:

$$
y \equiv\left(\bar{y}^{\text {bottom }}, \bar{y}^{\text {top }}, f^{\text {bottom }}\right)
$$

with $\bar{y}^{\text {bottom }}$ and $\bar{y}^{\text {top }}$ denoting the mean wage within the bottom and the top group, respectively, and with $f^{\text {bottom }}$ denoting the fraction of the population that belongs to the bottom group of wage earners. ${ }^{10}$

As shown in Kuhn (2011), the Gini coefficient $G$ in this simplified setup turns out to be equal to:

$$
G=f^{\text {bottom }}-q^{\text {bottom }}
$$

the absolute difference between the relative size of the bottom group and the wage share earned

\footnotetext{
${ }^{9}$ The main issue with this approximation is that the computation of the Gini coefficient based on aggregatelevel wage data necessarily ignores within-group wage differentials. For this reason, the Gini coefficient computed using aggregate-level data tends to underestimate the Gini coefficient based on individual-level data.

${ }^{10}$ Because there are only two groups of wage earners, and because they are assumed to be exhaustive, the two population shares must add up to one. This implies that $f^{\text {top }}=\left(1-f^{\text {bottom }}\right)$.
} 
by the bottom group. Further note that the mean wage in the population described by equation (1) is simply given by $\bar{y}=\bar{y}^{\text {bottom }} \cdot f^{\text {bottom }}+\bar{y}^{\text {top }} \cdot f^{\text {top }}$, which implies that the wage share earned by the bottom group is given by $q^{\text {bottom }}=\left(f^{\text {bottom }} \cdot \bar{y}^{\text {bottom }}\right) / \bar{y}$.

Moreover, note that it is always true that $\bar{y}^{\text {bottom }} \leq \bar{y}^{\text {top }}$ (the case of equality, i.e. $\bar{y}^{\text {bottom }}=\bar{y}^{\text {top }}$, would indicate that there is no wage inequality because we ignore all within-group inequality in wages). This implies that $q^{\text {bottom }}$ is always smaller than or equal to $f^{\text {bottom }}$ and that, consequently, the Gini coefficient $G$ always lies between 0 and $f^{\text {bottom }}$. Thus dividing $G$ by $f^{\text {bottom }}$ yields a normalized Gini coefficient:

$$
G^{\star}=G / f^{\text {bottom }}
$$

taking on values strictly between 0 and 1 (as the Gini coefficient based on individual-level wage data). $G=0$ would indicate that there is no (between-group) inequality in wages, while $G=1$ could only be attained if the bottom group of individuals receives a zero wage share.

\subsection{Measuring Individual-Level Inequality Perceptions}

The main idea in applying the framework to the perceived, rather than the objective, level of wage inequality is to acknowledge that individuals, at least potentially, have imperfect or biased information about the existing wage levels for the two groups. At the conceptual level, this implies that the wage shares of the two groups will be considered as individual-specific quantities in principle. ${ }^{11}$

Formally, let us assume that the following triplet of information is observed for each respondent - analogous to the case of objective wage information (i.e. compare equation (4) with equation (1) above):

$$
y_{i} \equiv\left(\bar{y}_{i}^{\text {bottom }}, \bar{y}_{i}^{\text {top }}, f^{\text {bottom }}\right)
$$

\footnotetext{
${ }^{11}$ The two population shares are treated as fixed parameters (i.e. $f_{\text {bottom }}$ does not vary across individuals), even though it is easy to imagine that individuals have different (and potentially biased) perceptions of these quantities as well. This contrasts with other frameworks used in the literature which rely on individuals' estimates of relative group sizes (e.g. Engelhardt and Wagener, 2014; Gimpelson and Treisman, 2015; Niehues, 2014). As mentioned in the introduction, the findings from Eriksson and Simpson (2012) and Chambers et al. (2014) suggest that the extent of inequality individuals perceive might differ, depending on whether the measurement is based on individuals' estimates of wages and/or relative group sizes.
} 
with $\bar{y}_{i}^{\text {bottom }}$ and $\bar{y}_{i}^{\text {top }}$, respectively, denoting the wage share going to the bottom and the top group of wage earners as perceived by a given individual $i$, and with $f^{\text {bottom }}$ denoting the relative size of the bottom group of wage earners. Thus note that the only difference to the measurement of wage inequality using objective data is that the framework allows people to have different wage perceptions. Note that the framework can also accommodate the case of no individuallevel misperceptions at all, in which case we would simply expect $G_{i}$ to have a degenerate distribution centered at the true value of $G$.

Further assuming that the different arguments of equation (4) have already been estimated (see section 3.3 below on how this is done in practice), individual-level Gini coefficients can easily be computed as follows:

$$
G_{i}=f^{\text {bottom }}-q_{i}^{\text {bottom }}
$$

where $q_{i}^{\text {bottom }}$ denotes the wage share the bottom group earns as perceived by individual $i$. As above, $f^{\text {bottom }}$ denotes the relative size of the bottom group. Thus, as in the case of objective wage data, the Gini coefficient is simply given by the difference between the population share of the bottom group and the wage share of the bottom group. ${ }^{12} G_{i}$ is best thought of as a summary measure of an individual's perception of wage differentials across occupations and it represents, in this sense, an individual's perception of inequality in market wages. Because individuals will tend to have different perceptions of group-specific wages, they will also differ regarding the perception of wage inequality. In contrast to the objective level of inequality, which can be described by a single Gini coefficient $G$, there will usually be a distribution of individual-level inequality perceptions, $f\left(G_{i}\right)$.

Finally, as in the case of objective wage data, division of $G_{i}$ by the relative size of the bottom group yields a normalized version of individual inequality perceptions:

$$
G_{i}^{\star}=G_{i} / f_{\text {bottom }}
$$

\footnotetext{
${ }^{12}$ In principle, and in contrast to the Gini coefficient describing the objective distribution of wages, the subjective Gini coefficient given by equation (5) can take on negative values because some individuals may believe that the wage share of the bottom group is larger than their actual population share (that is, $q_{i}^{\text {bottom }}$ can take on any value between zero and one). Empirically, as shown in table 1 below, this is true for a small fraction of the overall sample (less than $0.4 \%$ of the overall sample).
} 
taking on values less than or equal to 1 (see footnote 12 on the possibility of $G_{i}^{\star}$ taking on negative values).

\subsection{Subjectively Perceived Wage Levels}

A final issue that needs to be clarified is the construction of empirical counterparts of the three arguments on the right-hand size of equation (4), i.e. an individual's subjective perceptions of the wage level of the two groups of wage earners along with the relative size of the bottom group of wage earners. Remember that there are only four occupations for which respondents were asked to give wage estimates in each of the four waves of the survey, and I will thus only use data referring to these occupations.

Specifically, I calculate subjective wage estimates of a given individual $i$ for the two groups of wage earners as:

$$
\begin{aligned}
\bar{y}_{i}^{\text {bottom }} & =y_{i}^{\text {unskilled }}, \quad \text { and } \\
\bar{y}_{i}^{\text {top }} & =\frac{1}{3} \cdot\left(y_{i}^{\text {doctor }}+y_{i}^{\text {minister }}+y_{i}^{\text {chairman }}\right),
\end{aligned}
$$

respectively. That is, I simply use an individual's estimate of an unskilled worker's wage as his or her perception of the wage earned by the bottom group and, analogously, the average estimate of the wage of a doctor, a minister, and a chairman as a given individual's perception of the mean wage paid to the top group of wage earners.

The fraction of individuals belonging to the bottom group, $f^{\text {bottom }}$, is estimated from the observable distribution of individuals across different occupations in the following way:

$$
f^{\text {bottom }}=\frac{1}{n} \sum_{i=1}^{n} \mathbf{1}\left(\text { isco }_{i} \in[3,9]\right),
$$

with $\mathbf{1}(\cdot)$ denoting the indicator function, and with isco denoting an individual's major occupational code according to the International Standard Classification of Occupations (ISCO). According to this classification, major group 1 (i.e. isco =1) consists of "legislators, senior officials and managers" and major group 2 (i.e. isco $=2$ ) of "professionals". Even though $f^{\text {bottom }}$ does not vary across individuals, note that I estimate a different $f^{\text {bottom }}$ for each aggregate cell. ${ }^{13}$

\footnotetext{
${ }^{13}$ Estimated group shares do not change much over time and thus the results would hardly change if I only
} 
Finally note that it is possible to compute an empirical measure of an individual's perception of the overall wage level in his or her country of residence, analogous to the case of objective wage data (cf. section 3.1 above). Specifically,

$$
\bar{y}_{i}=\bar{y}_{i}^{\mathrm{bottom}} \cdot f^{\mathrm{bottom}}+\bar{y}_{i}^{\mathrm{top}} \cdot\left(1-f^{\mathrm{bottom}}\right)
$$

reflects the overall wage level as perceived by individual $i$. This implies that it will be not only be possible to compare a country's actual level of inequality with individual-level inequality perceptions, but also to compare a country's actual level of income with mean individual-level perceptions of the overall wage.

\section{Using Different Sets of Occupational Wage Estimates}

Given the way subjective inequality perceptions are constructed from the data, it is obvious that the set of occupations for which individual wage estimates are available is potentially important for the resulting distribution of inequality perceptions (that is, different sets of occupations will result in different group-specific wages, which in turn will lead to different estimates of inequality perceptions). As a robustness check, I thus also construct an alternative measure of inequality perceptions that uses all of the available wage estimates for people working in different occupations, instead of using only those wage estimates for the four occupations appearing in all waves of the survey (see table 1 below for a comparison between the two alternative constructions). However, because the alternative measure is based on different sets of occupations at different points in time, it potentially lacks comparability over time, compared to the baseline measure.

\subsection{Distributional Norms}

Finally, using an argument analogous to that used in constructing individual-level inequality perceptions, and because respondents in the ISSP surveys were not only asked about actual, but also about fair wages paid for in different occupations, it is possible to compute an empirical measure of individuals' distributional norms as well. The only difference compared to the

were to allow the population shares to vary across countries (but not over time within a given country). There are, however, substantial differences in $f_{\text {bottom }}$ across countries. 
construction of inequality perceptions is that it uses individuals' estimates of just, instead of actual, wages for people working in different occupations (which implies that distributional norms are measured as a Gini coefficient as well). Individual-level distributional norms thus reflect an individual's desired distribution of market wages, expressed in terms of a hypothetical level of inequality which is judged as just (see Kuhn, 2011, for additional details).

Besides being of interest on their own, distributional norms have been shown to be highly correlated with an individual's perception of the degree of wage inequality (Kuhn, 2011). While some of this correlation presumably reflects an anchoring effect, it certainly reflects variation due to common confounders, such as an individual's income or wealth, as well. From a practical point of view, this has the advantage that it allows me to control for economic resources for non-employed individuals in an indirect yet plausible way, and thus to include these individuals in the empirical analysis as well (cf. Kuhn, 2015). ${ }^{14}$

\section{The Diversity of Inequality Perceptions}

Table 1 presents a few overall descriptives (i.e. descriptives referring to the overall sample) for the variables of interest. Panel (a) first focuses on individuals' subjective perceptions of wage inequality. Individual inequality perceptions average 0.592 across all available countries and years (remember that inequality perceptions are measure in Gini points). Clearly, there is a lot of variation in the perception of wage inequality across individuals, as indicated by the corresponding standard deviation of about 0.202. Further note that there are only few individuals who do not perceive any wage differentials across the different occupations at all (only about 1 percent of the overall sample). Another obvious, yet somewhat counterintuitive feature, is that there is a small fraction of individuals with negative inequality perceptions (cf. footnote 12).

\section{Table 1}

Panel (b) of table 1 in turn shows descriptives for the two aggregate-level Gini coefficients describing the objective distribution of income in a given country and year (note that the

\footnotetext{
${ }^{14}$ This is similar in spirit to Dohmen et al. (2012), who use occupational prestige scores to control for individuals' income indirectly.
} 
descriptives in this case are based on variation across distinct aggregate-level cells only, not on individual-level data). The mean Gini coefficient before taxes and transfer payments equals 0.463, while the Gini after taxes and transfers averages 0.313.

Panel (c) presents summary statistics for the variables used as controls in the regression analysis below, namely: age (in years), a female dummy, individual-level distributional norms; and, at the aggregate level: a country's GDP per capita, its growth rate, its unemployment rate, and its labor force participation rate. The most notable finding here is the comparison of the average of distributional norms with the mean of inequality perceptions (note that a direct comparison is possible because the two measures are constructed in the same way, and thus both variables use the same scaling). The comparison suggests that the distribution of wages considered fair is considerably more equal than the perceived distribution of wages (0.409 versus 0.592 Gini points).

Finally, panel (d) of table 1 presents descriptives for two different variations in measured inequality perceptions, computed using different sets of occupational wage estimates (as discussed in section 3.3 above). Not surprisingly, the comparison between the two measures shows that they differ with respect to their mean value, as the distribution of inequality perceptions constructed using the full set of occupations shifted somewhat to the left (mean perceptions of 0.556 versus 0.592$)$. While this finding may be less relevant in the regression analysis because the two measures are highly correlated with each other $(\widehat{\rho}=0.917, p<0.01)$, it may be important as soon as the absolute level of individuals' inequality perceptions is relevant, such as when trying to quantify the overall degree of misperception (see section 5.5 below).

\section{$5 \quad$ Inequality and Inequality Perceptions}

The next section focuses on the empirical relation between the effective level of inequality (i.e. the level of inequality measured in an objective sense) in a given country and survey-year on the one hand, and individual-level, subjective perceptions of wage inequality on the other hand.

\subsection{Graphical Evidence}

I start with some simple graphical evidence to illustrate the strength of the empirical association between inequality and inequality perceptions. Specifically, figure 1 plots the aggregate-level 
means of subjective inequality perceptions against the corresponding aggregate-level Gini coefficients, either before or after taxes and transfer payments. In either case, note that there is a strong and positive correlation between mean perceptions of wage inequality and the objectively measured level of inequality.

Figure 1

While it is not surprising to find that the two measures are correlated with each other, it is nonetheless notable how strong the correlation at the aggregate level actually is, given that the two measures are based on entirely independent sources of data. The correlation coefficient equals 0.505 (with a p-value $<0.01$ ) in panel (a), and 0.465 (with a p-value $<0.01$ ) in panel (b).

Figure 2

Similarly, as mentioned above, it is also possible to compare individuals' estimates of the overall wage level prevailing in their country of residence with the corresponding per-capita GDP as a proxy for a country's mean wage. This is illustrated graphically in figure 2, which plots the natural logarithm of mean inequality perceptions against the natural logarithm of per-capita GDP in a given country $\times$ year. Again, there appears to be quite a strong positive, though insignificant, correlation between the two variables $(\widehat{\rho}=0.207$, with a p-value of 0.142$)$.

\subsection{Estimation Framework}

To quantify the strength of the empirical association between the objective level of inequality and subjective inequality perceptions, I will estimate a series of regression models which all use individual-level inequality perceptions as the dependent variable and objective measures of the aggregate-level of inequality as the main regressor(s). Specifically, these regression models will take on the following basic form:

$$
G_{i t}^{\star}=\beta_{0}+\beta_{1} G_{j[i] t}^{\text {before }}+\beta_{2} G_{j[i] t}^{\text {after }}+\beta_{3} x_{i t}+\beta_{4} z_{j[i] t}+\phi_{t}+\psi_{j[i]}+\epsilon_{i t}
$$

with the dependent variable $G_{i t}^{\star}$ representing normalized individual-level inequality perceptions of individual $i$ who participated in the survey in year $t$, as defined in equation (5) above. The 
regressor of key interest is either the Gini coefficient before and/or after taxes and transfer payments in country $j$ and year $t$, denoted by $G_{j[i] t}^{\text {before }}$ and $G_{j[i] t}^{\text {after }}$, respectively. The partial effect of inequality perceptions with respect to the objective level of inequality in a given country and year is of key interest in this context, and thus $\beta_{1}$ and/or $\beta_{2}$ are of primary interest in what follows. Both $\beta_{1}$ and $\beta_{2}$ are expected to be positive, but the size of the parameters is mainly an empirical issue. Most importantly perhaps, it is not obvious, ex-ante, whether the two parameters are smaller or larger than one. A coefficient about equal to one would indicate that the true level of inequality is reflected one-to-one in mean inequality perceptions, while a coefficient smaller (larger) than one would suggest that the effect of inequality on subjective perception is attenuated (amplified); due to, for example, biased coverage of the topic in the media (Petrova, 2008). The comparison between $\beta_{1}$ and $\beta_{2}$ is interesting as well, showing whether individuals' perceptions of wage inequality are shaped by the distribution before and/or after government intervention (in this regard, one would presumably expect that it is mainly the distribution after taxes and transfers which influences individuals' perceptions of wage inequality - even if most respondents in the survey were asked to estimate wages before taxes).

Most of the regression models will also include survey-year fixed effects, denoted by $\phi_{t}$, as well as a full set of country fixed-effects, denoted by $\psi_{j[i]}$. The fixed effects are important because they will absorb all systematic differences in inequality perceptions across countries and across years, independent of whether these differences are due to observable or unobservable factors. ${ }^{15}$ Finally, some of the more elaborated specifications will also include a few individualand/or aggregate-level controls, denoted by $x_{i t}$ and $z_{j[i] t}$ in equation (10) above, respectively. At the individual-level, additional controls are age (in years), a female dummy, as well as an individual's distributional norms (cf. section 3.4 above). Additional aggregate-level controls are a country's GDP per capita (in constant 2005 US dollars), its unemployment and labor force participation rate, as well as its growth rate (cf. section 2.2 above).

A final estimation issue relates to the fact that the regressor of interest varies at the aggregate-level only, while the dependent variable varies at the individual level. This might

\footnotetext{
${ }^{15}$ While it is possible to include a full set of country $\times$ survey-year fixed effects, note that the fixed effects will fully pick up any potential effect of aggregate-level inequality on inequality perceptions (i.e. it is not possible to estimate both a full set of fixed effects and the effect of any aggregate-level variable). Nonetheless, estimating such a specification is useful as a robustness check, as discussed in section 5.4 below.
} 
yield biased standard errors when the different levels of aggregation are neglected (e.g. Cameron and Miller, 2015; Moulton, 1990). To take this issue into account, I report standard errors that are clustered by country $\times$ survey-year, instead of conventional standard errors, throughout the empirical analysis (in the present context, this yields standard errors that are considerably larger than conventional standard errors).

\subsection{Main results}

Table 2 presents the main estimates describing the association between perceptions of wage inequality and a country's aggregate-level inequality. The first column shows the resulting point estimate when the Gini coefficient before taxes and transfers is the only regressor in the model. This simple specification yields a large and statistically significant point estimate of $\widehat{\beta}_{1}=1.701$ (with a cluster-robust standard error of 0.436 ), resulting in a highly significant estimate. Moreover, also note that this simple model has a comparatively high fit, with a resulting R-squared of almost $11 \%$. This estimate, of course, mirrors the pattern shown in figure 1, and it underlines the fact that mean subjective inequality perceptions are strongly correlated with the effective level of inequality (which in turn implies that individual-level perceptions of inequality are correlated with each other within aggregate cells). At the same time, it is also immediately evident that there is a potentially high degree of individual misperceptions, because the by far larger fraction of the overall variation in inequality perceptions remains unexplained by the variation in aggregate-level inequality.

\section{Table 2}

The second column adds country- as well as survey-year fixed effects. Not surprisingly, and consistent with the high intraclass-correlation documented in table 1 , this yields a much smaller point of $\beta_{1}$. The resulting point estimate of $\widehat{\beta}_{1}=0.336$ is only about one-fifth the size of the corresponding estimate from the first column and, moreover, it is no longer statistically significant at conventional levels. Interestingly, this specification confirms that there have been significant shifts in inequality perceptions over time (i.e. two of the three coefficients on the survey-year dummies are statistically significant, and a F-test on the joint significance of all three year dummies yields a p-value smaller than 0.0001), even conditional on the effective level of income inequality before taxes and transfers. This is an interesting finding because it suggests 
that there have been shifts in the mean perception of inequality unrelated to changes in the effective level of inequality (potentially reflecting, for example, an increased public awareness towards issues of economic inequality and/or an increased coverage of such issues in the media). Moreover, this specification also nets out any other existing (and time-invariant) differences across the different countries such as any existing and persistent differences in market beliefs and other ideological factors (the estimated country fixed-effects are reported in appendix table A.2).

Adding additional individual-level controls further reduces the estimated coefficient on the Gini before taxes and transfers, as shown in the third column of table 2. The resulting estimate of $\widehat{\beta}_{1}=0.262$ remains statistically insignificant, even though the standard error becomes smaller as additional controls are included (cluster-robust standard error of about 0.172). The individual-level controls have the expected sign, but only age and distributional norms reach statistical significance, while the coefficient on the female dummy remains statistically insignificant. As expected, there is a strong positive, and highly significant, association between distributional norms and inequality perceptions (cf. section 3.4). Also note that the three individual-level controls substantively increase the overall fit of the model.

Columns 4 to 6 basically replicate the analysis from the first three columns, but they replace the Gini coefficient before taxes and transfers with the Gini coefficient after taxes and transfers as the key regressor. The qualitative pattern across the different specifications turns out to be very similar, with the point estimate on the Gini becoming smaller as more controls are included in the regression model (i.e. $\widehat{\beta}_{2}$ becomes smaller when more controls are included). In the most demanding specification, shown in column $6, \widehat{\beta}_{2}$ equals 0.441 , with a cluster-robust standard error of 0.083 . This point estimate is, in contrast to the corresponding estimate from column 3, statistically significant (with a large robust t-value of about 5.3).

The final three columns of table 2 are again based on the same three sets of controls, but now I include both the Gini coefficient before as well as the Gini coefficient after taxes and transfer payments as regressors. While both Gini coefficients are estimated to have a significant effect on inequality perceptions when no additional controls are included, only the Gini coefficient after taxes and transfer payments appears to have a statistically significant effect in the more demanding specifications. Specifically, the point estimate associated with the 
Gini before taxes/transfers is essentially zero and statistically insignificant in the final column while, on the other hand, $\widehat{\beta}_{2}$ remains large and statistically significant (also note that the point estimate associated with the Gini after taxes/transfers from column 9 is almost identical to that from column 6).

Taken together, the estimates presented in table 2 yield several interesting insights. First, subjective perceptions of wage inequality and aggregate-level inequality are quite strongly correlated with each other. Second, additional explanatory variables pick up a substantive part not only of the overall variation in inequality perceptions, but also of the association between subjective inequality perceptions and aggregate-level inequality. Third, only the Gini coefficient after taxes and transfer payments appears to have a significant association with inequality perceptions when controlling for additional explanatory variables. Finally, note that the point estimate from the preferred specification of column 9 is not only significantly larger than zero; it is also significantly less than one, suggesting that the impact of inequality on perceptions is muted.

\subsection{Robustness}

Table 3 presents a few robustness checks, documenting that the main estimates are robust to a variety of alternative model specifications (for the ease of comparison, the first column of table 3 simply replicates the baseline estimates from column 9 of table 2).

In a first robustness check, columns 2 to 4 report estimates that use slightly different parameterizations of the objective level of inequality. Specifically, the estimates from the second column are from a regression which includes the difference between the Gini after and the Gini before taxes and transfers, $\Delta$ Gini for short, as key regressor. The estimated coefficient associated with $\Delta$ Gini turns out to be positive, indicating that inequality perceptions tend to be lower where and/or when there is a large difference between the Gini after and the Gini before taxes and transfers (i.e. inequality perceptions tend to be lower when there is more redistribution). A similar estimate results when the relative difference (i.e. $\Delta$ Gini divided by the Gini before taxes and transfers) is included as main regressor, as shown in column 3. The fourth column includes both $\Delta$ Gini and the Gini after taxes and transfers. In this specification, the coefficient on the level of inequality remains large and statistically significant, while the 
coefficient associated with the relative difference is insignificant and close to zero.

\section{Table 3}

Most of the remaining columns of table 3 present estimates that either use a slightly different or an expanded set of control variables. More specifically, column 5 uses a more flexible specification with respect to the individual-level controls than the baseline model, including age squared as well as interaction terms between the female dummy and age, age squared, and distributional norms. This yields an estimate very close to the baseline estimate. In column 6 , I use the natural logarithm of the two objective Gini coefficients. This specification is mainly a test against potential functional-form misspecification of the regression model with respect to the main regressors. Again, this does not change the qualitative pattern of the estimates, but it does - by construction - change the size of the estimated coefficient of interest. ${ }^{16}$ Column 7 again uses the baseline specification, but adds a couple of aggregate-level controls (note that this reduces the sample size by about one-sixth, compared to the baseline specification). Again, however, this does not change the point estimate associated with the Gini coefficient after taxes and transfers by much $\left(\widehat{\beta}_{2}=0.388\right.$ with a robust standard error of 0.13$)$.

The estimates presented in column 8 are based on a restricted set of the overall sample. Specifically, this specification only includes respondents living in one of the Anglo-American or Western-European countries - the idea here being that the estimated association between inequality perceptions and aggregate-level inequality might differ across countries (cf. Isaksson and Lindskog, 2009). Indeed, this specification yields a somewhat larger point estimate of $\widehat{\beta}_{2}=0.632$ but, again, the estimate is not statistically different from the baseline estimate of column 1.

The specification in column 9 again uses the full sample, and it includes a full set of country $\times$ survey-year fixed effects (i.e. the specification allows for time-variant country fixed effects). Because this specification absorbs all aggregate-level variation in inequality perceptions, a separate estimation of the coefficients on the two Gini coefficients is no longer possible. However, it is still informative to see that this model yields similar-sized estimates on the individual-level regressors as well as a model fit close to the baseline specification.

\footnotetext{
${ }^{16}$ The point estimate of column $6\left(\widehat{\beta}_{2}=0.184\right)$ directly estimates the semi-elasticity of inequality perceptions with respect to aggregate-level inequality (i.e. doubling aggregate-level inequality is associated with an increase in inequality perceptions by 0.184 Gini points). The estimates from column 1 imply an approximate semielasticity of about 0.139 , which is consistent with the point estimate from column 6 .
} 
Finally, the estimates shown in the last column replicate the specification of the baseline model, but they use an alternative measure of inequality perceptions (i.e. the last column uses the alternative version of individual-level inequality perceptions, as discussed in section 3.3, as the dependent variable). This yields a somewhat smaller point estimate on the Gini after taxes and transfers $\left(\widehat{\beta}_{2}=0.396\right)$, but the point estimate is again not statistically significantly different from the baseline estimate of column 1.

\subsection{Misperceptions of Wage Inequality}

An additional issue of interest is whether people tend to over- or to underestimate the existing level of inequality. To approach this question empirically, a direct quantification of individual misperceptions of the true level of inequality is necessary. However, as mentioned in the introduction, quantifying the degree of misperception is presumably more tentative than estimating the association between subjective inequality perceptions and aggregate-level inequality.

Empirically, the most obvious choices to estimate individual-level misperceptions are:

$$
\begin{aligned}
& m_{i j t}=G_{i j t}^{\star}-G_{j t}, \quad \text { or } \\
& m_{i j t}=\left(G_{i j t}^{\star}-G_{j t}\right) / G_{j t},
\end{aligned}
$$

that is, either the absolute or the relative difference between individual-level perceptions of wage inequality and the objective level of inequality in a given country and year, measured by either the Gini before or the Gini after taxes and transfer payments.

Figure 3

Figure 3 shows the estimated frequency distributions of the two variants of misperceptions, with absolute deviations shown in panel (a) and with relative deviations shown in panel (b). In both figures, the solid line refers to deviations from the Gini before taxes and transfers, while the dashed line refers to deviations from the Gini after taxes and transfers. The overall pattern evident from figure 3 is that individuals, on average, tend to overestimate the prevailing level of inequality or, at least, that there is no evidence in support of people underestimating the prevailing level of inequality. ${ }^{17}$ Again, this is consistent with previous studies (Chambers et al.,

\footnotetext{
${ }^{17}$ Again, one might argue that the set of occupational wage estimates used to construct individual-level
} 
2014; Eriksson and Simpson, 2012; Gimpelson and Treisman, 2015).

\section{The Importance of Endogenous Reference Groups}

Because all respondents were asked to estimate wages for the same set of occupations in any given country and year, issues with endogenous reference groups (e.g. Clark and Senik, 2010) are arguably much less important than in other settings. However, there certainly are regional differences in the level of occupational wages, and individuals may actually think about wage levels in the region they live in, rather than about national averages, when asked to estimate wages for different occupations (see, e.g., Clark et al., 2009; Luttmer, 2005).

\section{Table 4}

To probe the importance of this issue, I ran an additional series of regression models including different sets of fixed effects (see appendix table 4). These regressions provide a decomposition of the overall variation of inequality perceptions into variation within versus variation across aggregate-level cells (the first column provides, as a benchmark, statistics from a regression including but an overall constant). ${ }^{18}$ The second column shows that the inclusion of both country and survey-year fixed effects picks up about one-third of the overall variation in inequality perceptions. As shown in the third column, using a full set of interacted country $\times$ year fixed effects only modestly increases the fit of the model. More interestingly, however, column 4 shows that the inclusion of regions-within-countries $\times$ survey-year fixed effects only marginally increases the model fit compared to column 3, although the number of fixed effects estimates increases more than ten-fold (the R-squared only increases from 0.36 to 0.374 ). This suggests that there are no obvious issues with respondents estimating regional rather than national-level wages for the different occupations.

inequality perceptions are important for the observed level of inequality misperceptions. Clearly, different sets of occupations do imply different distributions of inequality perceptions, but they all appear consistent with respect to the finding that, if anything, people tend to over- rather than underestimate the prevailing level of inequality (see appendix figure A.1).

${ }^{18}$ Note that this decomposition is informative about the extent of individual misperceptions of inequality because, if there were no individual misperceptions of wage inequality at all, we should observe no individual variation in the perception of inequality within a given aggregate cell. Any substantial residual variation remaining after netting out variation in inequality perceptions across the aggregate cells thus suggests that individuals have misperceptions of inequality. Also note that there is no need for any additional controls for this step of the analysis. 
As argued above, due to the design of the survey, endogenous reference groups are not expected to play a key role. However, it is straightforward to see whether this presumption is actually true or not, and thus the remaining columns of table 4 show various regressions which additionally include different sets of occupation fixed effects. First, columns 5 and 6 simply add fixed effects for respondents' occupation, without any substantive impact on model fit (the R-squared does hardly change). There is an increase in the fit of the model once I include sets of fully interacted fixed effects, but the increase in the R-squared in these cases is likely due to the large number of different fixed effects estimated, relative to the overall sample size. Moreover, note that a significant fraction of residual variation remains even in the two final specifications.

\section{Attitudes to Social Inequality}

A final issue that I want to address is whether the distinction between the objective level of inequality and individuals' subjective perception of inequality makes any difference when focusing on inequality as an explanatory variable, such as when thinking about the impact of inequality on attitudes. One straightforward possibility to approach this question empirically is to use both subjective inequality perceptions and some objective, aggregate-level measure of inequality as regressors at the same time.

In the following, I will thus estimate an additional series of regression models taking on the following common form:

$$
a_{i t}=\alpha_{0}+\alpha_{1} G_{i t}^{\star}+\alpha_{2} G_{j[i] t}^{\mathrm{after}}+\alpha_{3} x_{i t}+\phi_{t}+\psi_{j[i]}+\epsilon_{i t}
$$

with the dependent variable $a_{i t}$ denoting attitudes towards social inequality of individual $i$ in survey-year $t$. More specifically, table 5 reports estimates for three different measures of attitudes to inequality, namely: (i) individuals' evaluation of whether income inequality in their country of residence is too large, (ii) their stated support of government intervention to reduce income differences, and (iii) their stated support of progressive taxation (see Kuhn, 2015, for a more comprehensive analysis of the effect of inequality perceptions on natives' attitudes to 
inequality, using a much broader set of attitudinal measures). ${ }^{19}$ All three dependent variables have been recoded such that higher values indicate, respectively, a more critical perception of the prevailing level of wage inequality or a stronger support of either government intervention or progressive taxation. I therefore expect both $\alpha_{1}$ and $\alpha_{2}$ to be positive throughout. ${ }^{20}$ All the control variables appearing on the right-hand side of equation (12) were already defined earlier (see section 5.2 above). Because the previous findings (cf. table 2) suggest that inequality perceptions are mainly/only influenced by the distribution of economic resources after taxes and transfers, I only include $G_{j[i] t}^{\text {after }}$ as regressor; however, I also checked that the results do not change when the Gini before taxes and transfers is included as regressor as well (see appendix table A.3).

\section{Table 5}

The first three columns of table 5 show the corresponding estimates of individuals' normative evaluation of the perceived overall level of income inequality. The first column, which only considers individual-level inequality perceptions, yields a point estimate of $\widehat{\alpha}_{1}=1.145$. With a cluster-robust standard error of about 0.104 , this point estimate is significant at every conventional level of statistical significance. As expected, a higher perceived level of wage inequality is associated with respondents being more likely to think that the existing income difference in their country of residence is too large. The second column includes the aggregate-level Gini coefficient after taxes/transfers as key regressor instead of inequality perceptions. This specification yields a significant point estimate of $\widehat{\alpha}_{2}=1.295$ (with a cluster-robust standard error of 0.510 ), which appears to be consistent with the estimate from column 1 . Column 3 includes both variables at once, yielding a positive coefficient for both inequality perceptions and the aggregate-level Gini coefficient. However, only the coefficient associated with individuallevel inequality perceptions turns out to be statistically significant $\left(\widehat{\alpha}_{1}=1.136\right.$, with a robust standard error of 0.106$)$.

\footnotetext{
${ }^{19}$ The exact wording of the corresponding items is as follows: (i) "Income differences in (respondent's country) are too large" (five possible answer categories, ranging from "strongly agree" to "strongly disagree"), (ii) "Government should reduce income differences" (with the same possible answers as in (i)), and (iii) "Should people with high incomes pay more taxes" (five possible answers, ranging from "much larger share" to "much smaller share").

${ }^{20}$ As a simple robustness check, I also estimated similar regressions using binary variables (indicating a respondent's agreement with the underlying survey item) as dependent variables, yielding qualitatively identical results. Moreover, estimation by ordered probit also yields qualitatively identical results. These additional estimates are shown in appendix table A.4.
} 
Columns 4 to 6 report estimates for individuals' support of government intervention, using the same set of specifications as in the preceding three columns. The fourth column shows that there is again a positive, and highly significant, association between inequality perceptions and individuals' belief that the state should reduce income differences $\left(\widehat{\alpha}_{1}=0.994\right.$ with a robust standard error of 0.112 ). The next column shows that there is also a positive, though insignificant, association with the aggregate-level Gini coefficient after taxes and transfers $\left(\widehat{\alpha}_{2}=\right.$ 0.433 , with a robust standard error of about 0.55$)$. The sixth column shows that, similar to the first panel of table 5, only individual-level perceptions of wage inequality have a statistically significant effect when both inequality perceptions and the aggregate-level of inequality are included as explanatory variables at the same time.

Finally, the remaining three columns of table 5 report estimates with respect to individuals' support of progressive taxation (again using the same three specifications as above). Column 7 yields a positive and highly significant point estimate of $\widehat{\alpha}_{1}=1.162$ (robust standard error of 0.112 ), but - similar to the preceding panel - there is no statistically significant association with the aggregate-level Gini coefficient, as shown in column 8 (again, however, the point estimate does have the expected positive sign). Finally, column 9 shows that the coefficient on inequality perceptions again remains statistically significant when both inequality perceptions and the aggregate-level of inequality are included as regressors.

It is also worth emphasizing that, for each of the three outcomes, the effect of inequality perceptions on attitudes is not only statistically significant, but also quantitatively important. Specifically, the estimates of column $3(6,9)$ imply an approximate elasticity of attitudes with respect to inequality perceptions, evaluated at mean values, of about $0.163(0.16,0.207)$.

\section{Table 6}

One potential concern with the estimates from table 5 is, however, that they are biased because of reverse causality, which would imply that the estimates potentially reflect that individuals with different attitudes towards inequality perceive a different level of inequality rather than the other way around. Table 6 therefore presents two-stage least squares (2SLS) estimates of the effect of inequality perceptions on attitudes, using two different instruments (the first column in each panel replicates the estimates from table 5). In the first case, and relying on the finding from table 5 that the aggregate-level of inequality does not appear 
to have an impact on attitudes conditional on subjective inequality perceptions, I use the aggregate-level Gini coefficient after taxes and transfers as instrument for individual-level inequality perceptions. The second instrument uses mean subjective inequality perceptions in regions-within-countries $\times$ survey-years, constructed directly from the survey data, as instrument for an individual's inequality perception (similar to Kuhn, 2015). ${ }^{21}$ Table 6 shows that the 2SLS estimates are generally consistent with the main estimates from table 5, yielding essentially the same qualitative pattern of estimates (in two cases, however, 2SLS estimates using the aggregate-level Gini coefficient as instrument turn out insignificant). Moreover, most 2SLS estimates for each of the three outcomes considered turn out to be larger than the simple estimates from table 5, suggesting that the simple estimates are actually downward biased (also note that both instruments have a large first-stage effect, as indicated by the corresponding first-stage F-statistic which tests for the strength of the instrument). ${ }^{22}$

Taken together, these results yield several interesting insights. First, and consistent with previous evidence (e.g. Gimpelson and Treisman, 2015; Kuhn, 2015; Schneider, 2012), I find that subjective inequality perceptions are more important - in a statistical sense - than aggregatelevel measures of inequality for predicting the observed variation in individual attitudes to social inequality. ${ }^{23}$ This finding that inequality perceptions affect individuals' attitudes towards social inequality is consistent across the different outcome measures, robust to different specification checks, and does not appear to be driven by reverse causality. Secondly, comparing the estimates for the same outcome across the different specifications suggests that the effect of aggregate-level inequality runs mainly through its effect on inequality perceptions; a finding which is highly intuitive and consistent with previous results (cf. section 5). Third, and

\footnotetext{
${ }^{21}$ Mean inequality perceptions are only marginally influenced by individual inequality perceptions, but one might argue that a respondent's perception of wage inequality is influenced by the perceptions of people around him or her (for example his or her colleagues at work). One potential issue with this instrument is that there might be a direct (positive) effect on individuals' attitudes, which would bias the 2SLS estimates (upward). On the other hand, remember that the results from table 4 suggest that regional differences (within countries) in inequality perceptions do not appear to be especially relevant, conditional on country and survey-year fixed effects.

${ }^{22} \mathrm{I}$ also estimated the models using both instruments at the same time and based on different estimation methods (see appendix table A.5). The resulting point estimates are close to the 2SLS estimates using only mean subjective inequality perceptions in regions-within-countries $\times$ survey-year as instrument. Moreover, I cannot reject the null hypothesis that the overidentifying restrictions are valid in these cases, supporting the credibility of the 2SLS estimates.

${ }^{23}$ For each of the three outcomes of table 5, I also estimated a regression specification including a full set of country $\times$ survey-year fixed effects (see, again, appendix table A.3). In each case, the estimates turn out very similar to those from table 5, further strengthening the case that attitudes towards inequality are primarily driven by the perception of inequality, rather than by the true level of inequality.
} 
finally, the results also show that using some aggregate-level measures of inequality instead of individual-level inequality perceptions does not necessarily lead to the same qualitative conclusions: while there is a strong positive effect of inequality perceptions on both the general support of government redistribution and progressive taxation, the corresponding estimates using aggregate-level inequality turn out to be insignificant.

\section{Conclusions}

In this paper I present a simple, yet intuitive conceptual framework suitable for measuring individual-level perceptions of wage inequality using a small set of simple survey questions asking individuals about their perception of wages paid for in different occupations. The framework is illustrated using internationally comparable survey data from the ISSP cumulation on social inequality, which covers a large number of different countries over a relatively long period of time with a total of more than 65,000 individual observations from 23 different countries and from up to 4 different points in time.

The main part of the empirical analysis focuses on the association between aggregate-level measures of inequality with individual-level perceptions of wage inequality using a series of descriptive regression models. Not surprisingly, and in line with previous evidence on the subject (Gimpelson and Treisman, 2015; Loveless and Whitefield, 2011), I find that the true level of inequality is strongly and positively associated with subjective inequality perceptions. ${ }^{24}$ This result turns out to be robust to a variety of specification checks (including, for example, alternative parameterizations of aggregate-level inequality). At the same time, there often is a large discrepancy between the effective level of inequality and an individual's subjective perception of inequality and, on average, it appears that people tend to overestimate the prevailing level of inequality, a finding which is again consistent with previous results (Chambers et al., 2014; Eriksson and Simpson, 2012; Gimpelson and Treisman, 2015).

The final part of the empirical analysis shows that individuals' attitudes towards social inequality are strongly associated with both inequality perceptions and the objective level of inequality when considered separately, but only with inequality perceptions when the two vari-

\footnotetext{
${ }^{24}$ Moreover, the finding of such a close association between inequality perceptions and aggregate-level inequality, using entirely independent sources of data, shows that simple survey-items are sometimes surprisingly powerful indicators of even complex economic phenomena.
} 
ables are considered simultaneously - which is consistent with the intuition that the effect of aggregate-level inequality runs indirectly, through its impact on individuals' inequality perceptions. This effect turns out to be robust to a variety of specification checks, and it also holds when potential bias due to reverse causality is taken into account. It also confirms similar conclusions from several previous studies, using in part different and independent sources of data and alternative measurement frameworks (e.g. Gimpelson and Treisman, 2015; Kuhn, 2015; Schneider, 2012).

Finally, the more general finding that the true level of inequality is strongly correlated with individuals' perceptions of wage inequality is in line with similar results from diverse contexts showing that the political-economic context partially shapes individuals' beliefs, perceptions and preferences (e.g. Di Tella et al., 2007; Giuliano and Spilimbergo, 2014; Oto-Peralías, 2015). 


\section{References}

Alesina, A. and Angeletos, G.-M. (2005). Fairness and Redistribution. American Economic Review, 95(4), 960-980.

Alesina, A. and Fuchs-Schündeln, N. (2007). Good-bye Lenin (or not?): The effect of communism on people's preferences. American Economic Review, 97(4), 1507-1528.

Bénabou, R. and Tirole, J. (2006). Belief in a Just World and Redistributive Politics. Quarterly Journal of Economics, 121(2), 699-746.

Cameron, A. C. and Miller, D. L. (2015). A practitioner's guide to cluster-robust inference. Journal of Human Resources, 50(2), 317-372.

Card, D., Mas, A., Moretti, E., and Saez, E. (2012). Inequality at Work: The Effect of Peer Salaries on Job Satisfaction. American Economic Review, 102(6), 2981-3003.

Chambers, J. R., Swan, L. K., and Heesacker, M. (2014). Better off than we know distorted perceptions of incomes and income inequality in America. Psychological Science, 25(2), 613-618.

Clark, A. and Senik, C. (2010). Who compares to whom? The anatomy of income comparisons in Europe. Economic Journal, 120(544), 573-594.

Clark, A. E., Westergård-Nielsen, N., and Kristensen, N. (2009). Economic satisfaction and income rank in small neighbourhoods. Journal of the European Economic Association, 7(2-3), $519-527$.

Clark, A. E., Masclet, D., and Villeval, M. C. (2010). Effort and comparison income: Experimental and survey evidence. Industrial \& Labor Relations Review, 63(3), 407-426.

Cornelissen, T., Himmler, O., and Koenig, T. (2011). Perceived unfairness in CEO compensation and work morale. Economics Letters, 110(1), 45-48.

Cruces, G., Perez-Truglia, R., and Tetaz, M. (2013). Biased perceptions of income distribution and preferences for redistribution: Evidence from a survey experiment. Journal of Public Economics, 98, 100-112.

Di Tella, R., Galiani, S., and Schargrodsky, E. (2007). The formation of beliefs: Evidence from the allocation of land titles to squatters. Quarterly Journal of Economics, 122(1), 209-241.

Dohmen, T., Falk, A., Huffman, D., Marklein, F., and Sunde, U. (2009). Biased probability judgment: Evidence of incidence and relationship to economic outcomes from a representative sample. Journal of Economic Behavior \& Organization, 72(3), 903-915.

Dohmen, T., Falk, A., Huffman, D., and Sunde, U. (2012). The intergenerational transmission of risk and trust attitudes. Review of Economic Studies, 79(2), 645-677.

Dube, A., Giuliano, L., and Leonard, J. (2015). Fairness and frictions: The impact of unequal raises on quit behavior. IZA Discussion Paper No. 9149.

Engelhardt, C. and Wagener, A. (2014). Biased perceptions of income inequality and redistribution. CESifo Working Paper Series.

Eriksson, K. and Simpson, B. (2012). What do Americans know about inequality? It depends on how you ask them. Judgment and Decision Making, 7, 741-745. 
Gastwirth, J. and Glauberman, M. (1976). The Interpolation of the Lorenz Curve and Gini Index from Grouped Data. Econometrica, 44(3), 479-483.

Gemmell, N., Morrissey, O., and Pinar, A. (2004). Tax perceptions and preferences over tax structure in the United Kingdom. Economic Journal, pages 117-138.

Gimpelson, V. and Treisman, D. (2015). Misperceiving inequality. IZA Discussion Paper No. 9100.

Giuliano, P. and Spilimbergo, A. (2014). Growing up in a recession. Review of Economic Studies, 81(2), 787-817.

Isaksson, A. and Lindskog, A. (2009). Preferences for redistribution-A country comparison of fairness judgements. Journal of Economic Behavior \& Organization, 72(3), 884-902.

ISSP Research Group (2014a). International Social Survey Programme: Social Inequality I-IV - ISSP 1987-1992-1999-2009. GESIS Data Archive, Cologne. ZA5890 Data File Version 1.0.0.

ISSP Research Group (2014b). International Social Survey Programme: Social Inequality I-IV add on - ISSP 1987-1992-1999-2009. GESIS Data Archive, Cologne. ZA5891 Data file Version 1.1.0.

Jasso, G. (1999). How Much Injustice is There in the World? Two New Justice Indexes. American Sociological Review, 64(1), 133-168.

Kakwani, N. and Podder, N. (1973). On the Estimation of Lorenz Curves from Grouped Observations. International Economic Review, 14(2), 278-92.

Kelley, J. and Evans, M. (1993). The Legitimation of Inequality: Occupational Earnings in Nine Nations. American Journal of Sociology, 99(1), 75-125.

Kluegel, J. R. and Smith, E. R. (1981). Beliefs about stratification. Annual Review of Sociology, pages $29-56$.

Kuhn, A. (2011). In the eye of the beholder: Subjective inequality measures and individuals' assessment of market justice. European Journal of Political Economy, 27(4), 625-641.

Kuhn, A. (2013). Inequality perceptions, distributional norms, and redistributive preferences in East and West Germany. German Economic Review, 14(4), 483-499.

Kuhn, A. (2015). The Subversive Nature of Inequality: Subjective Inequality Perceptions and Attitudes to Social Inequality. IZA Discussion Paper No. 9406.

Kuziemko, I., Norton, M. I., and Saez, E. (2015). How elastic are preferences for redistribution? evidence from randomized survey experiments. American Economic Review, 105(4), 14781508.

Loveless, M. and Whitefield, S. (2011). Being unequal and seeing inequality: Explaining the political significance of social inequality in new market democracies. European Journal of Political Research, 50(2), 239-266.

Luttmer, E. (2005). Neighbors as Negatives: Relative Earnings and Well-Being. Quarterly Journal of Economics, 120(3), 963-1002.

Moulton, B. (1990). An illustration of a pitfall in estimating the effects of aggregate variables on micro units. Review of Economics and Statistics, 72(2), 334-338. 
Niehues, J. (2014). Subjective perceptions of inequality and redistributive preferences: An international comparison. IW-TRENDS Discussion Papers Nr. 2.

Norton, M. I. and Ariely, D. (2011). Building a better America - One wealth quintile at a time. Perspectives on Psychological Science, 6(1), 9-12.

Odermatt, R. and Stutzer, A. (2015). (Mis-)Predicted Subjective Well-Being Following Life Events. IZA Discussion Paper No. 9252.

Olken, B. (2009). Corruption perceptions vs. corruption reality. Journal of Public Economics, 93(7-8), 950-964.

Osberg, L. and Smeeding, T. (2006). "Fair" Inequality? Attitudes toward Pay Differentials: The United States in Comparative Perspective. American Sociological Review, 71(3), 450473.

Oto-Peralías, D. (2015). The Long-Term Effects of Political Violence on Political Attitudes: Evidence from the Spanish Civil War. Kyklos, 68(3), 412-442.

Petrova, M. (2008). Inequality and media capture. Journal of Public Economics, 92(1), 183212.

Pfeifer, C. (2015). Unfair wage perceptions and sleep: Evidence from German survey data. IZA Discussion Paper No. 9317.

Schneider, S. M. (2012). Income inequality and its consequences for life satisfaction: what role do social cognitions play? Social Indicators Research, 106(3), 419-438.

Senik, C. (2005). Income distribution and well-being: what can we learn from subjective data? Journal of Economic Surveys, 19(1), 43-63.

Verme, P. (2011). Life satisfaction and income inequality. Review of Income and Wealth, 57(1), $111-127$. 


\section{Tables and Figures}

Table 1: Descriptives

\begin{tabular}{|c|c|c|c|}
\hline Variable & Mean & $\begin{array}{l}\text { Standard } \\
\text { deviation }\end{array}$ & $\begin{array}{l}\text { Intraclass } \\
\text { correlation }\end{array}$ \\
\hline \multicolumn{4}{|l|}{ (a) Individual-level perceptions of wage inequality } \\
\hline $\begin{array}{l}\text { Inequality perceptions } \\
\mathbf{1}(\text { inequality perception }<0) \\
\mathbf{1}(\text { inequality perception }=0) \\
\mathbf{1}(\text { inequality perception }>0)\end{array}$ & $\begin{array}{l}0.592 \\
0.003 \\
0.001 \\
0.996\end{array}$ & $\begin{array}{l}0.202 \\
0.054 \\
0.026 \\
0.060\end{array}$ & 0.340 \\
\hline \multicolumn{4}{|l|}{ (b) Aggregate-level statistics on inequality } \\
\hline $\begin{array}{l}\text { Gini coefficient, before taxes/transfers } \\
\text { Gini coefficient, after taxes/transfers }\end{array}$ & $\begin{array}{l}0.463 \\
0.312\end{array}$ & $\begin{array}{l}0.040 \\
0.067\end{array}$ & \\
\hline \multicolumn{4}{|l|}{ (c) Other individual-and aggregate-level controls } \\
\hline $\begin{array}{l}\text { Age (in years) } \\
\text { Female (yes = 1) } \\
\text { Distributional norms } \\
\text { Per-capita GDP (in constant } 2005 \text { US dollars) } \\
\text { Growth rate } \\
\text { Unemployment rate } \\
\text { Labor force participation rate }\end{array}$ & $\begin{array}{r}45.540 \\
0.514 \\
0.409 \\
29,037.305 \\
0.479 \\
8.272 \\
71.949\end{array}$ & $\begin{array}{r}16.466 \\
0.500 \\
0.203 \\
13,055.295 \\
3.985 \\
3.327 \\
5.413\end{array}$ & $\begin{array}{l}0.030 \\
0.009 \\
0.248\end{array}$ \\
\hline \multicolumn{4}{|l|}{ (d) Inequality perceptions (alternative construction) } \\
\hline Inequality perceptions & 0.556 & 0.202 & 0.381 \\
\hline
\end{tabular}

Notes: The table shows descriptives for the overall sample $(n=64,465$ in the case of individual-level variables; aggregate-level variables refer to 55 distinct aggregate cells at the country $\times$ survey-year level). Variable definitions and data sources are given in the main text. $\mathbf{1}(\cdot)$ denotes the indicator function. 


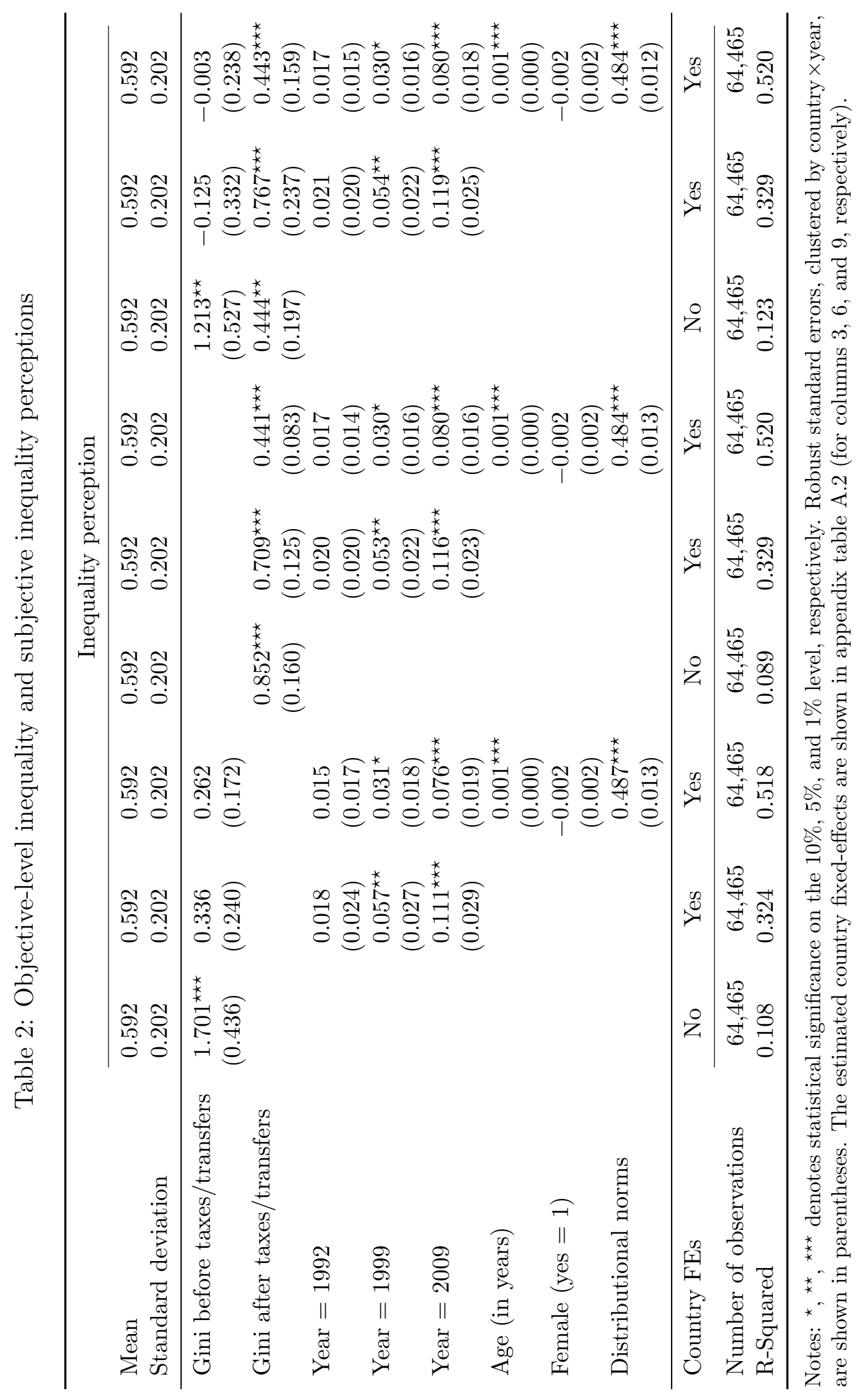




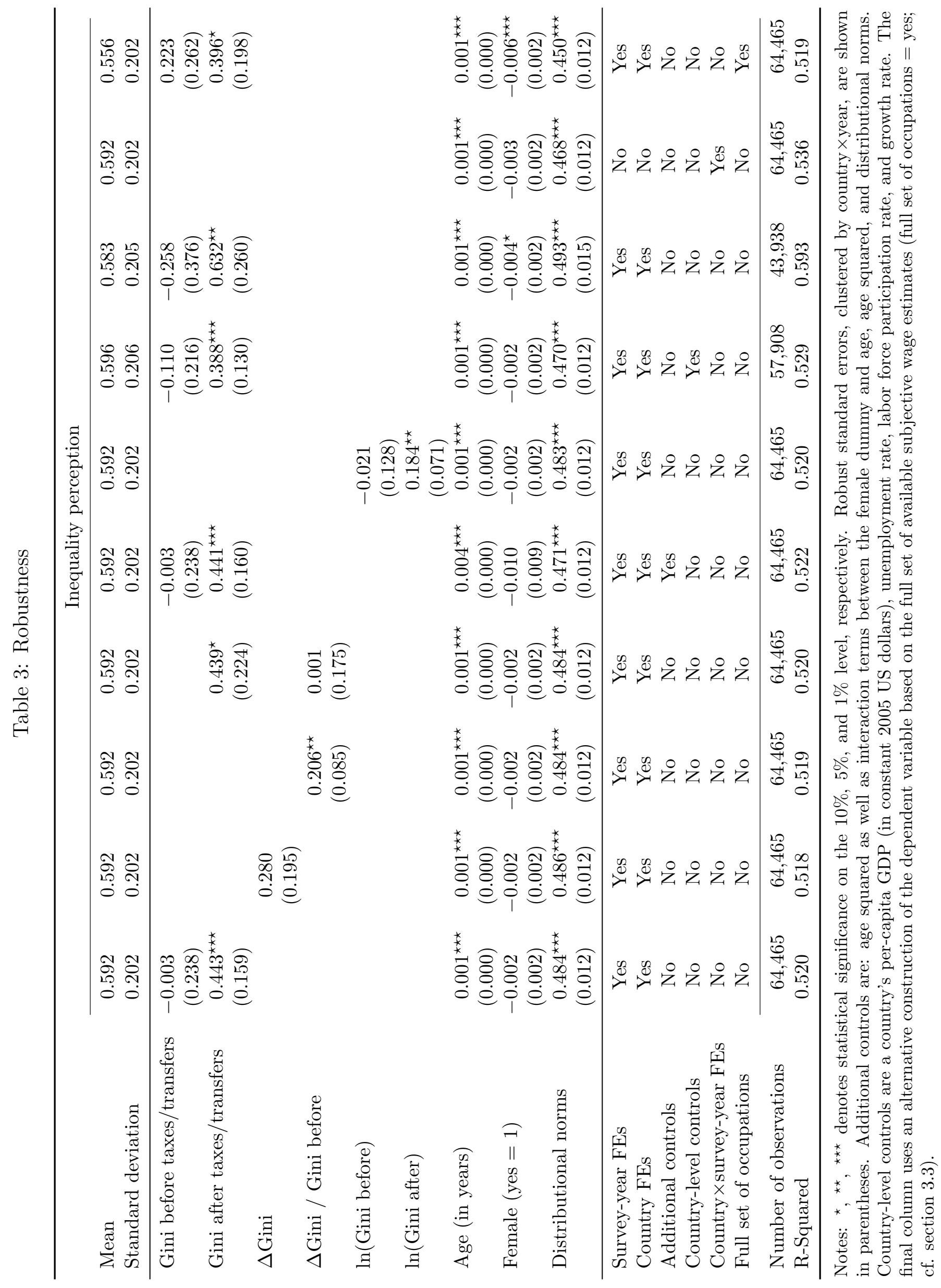




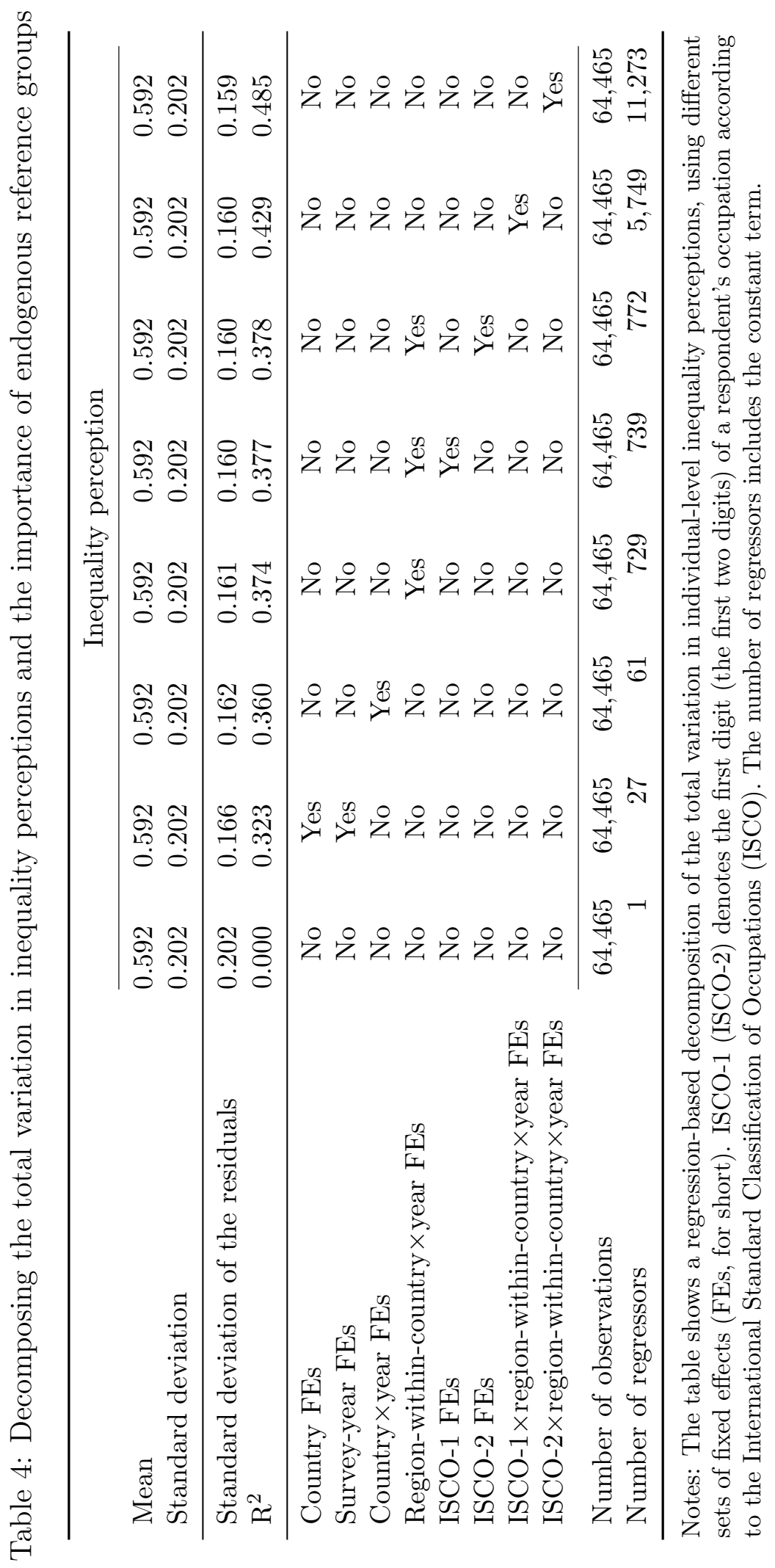




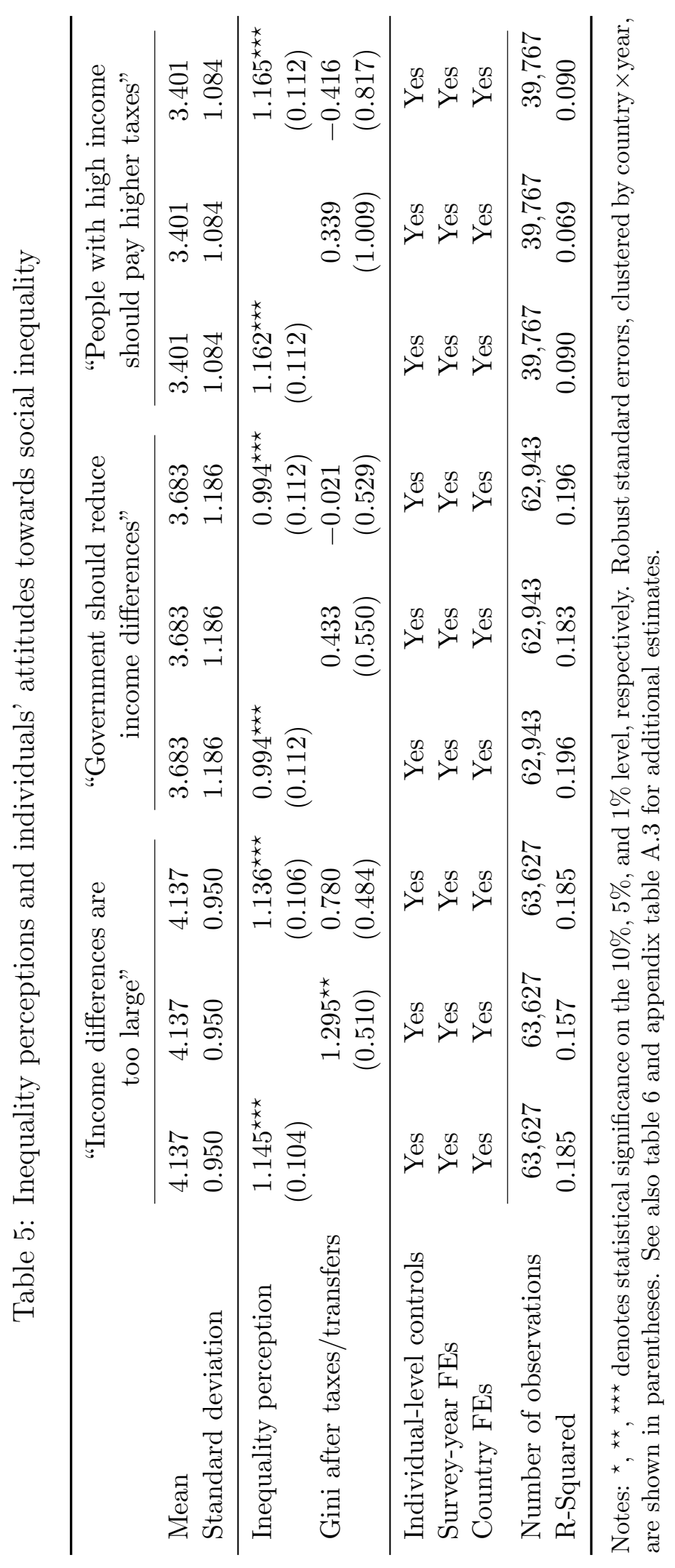




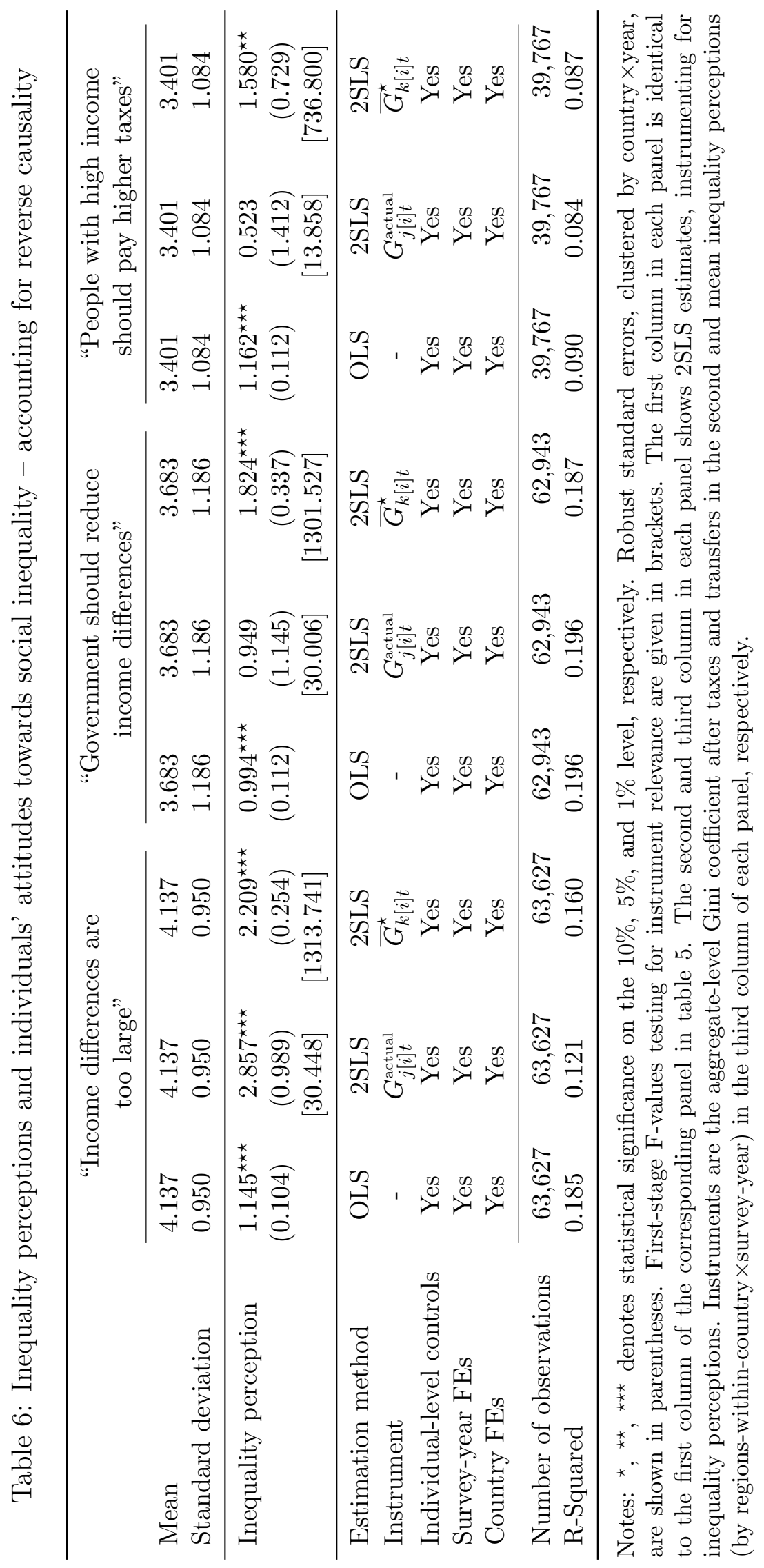


Figure 1: Mean subjective inequality perceptions and aggregate-level inequality at the country $\times$ survey-year level

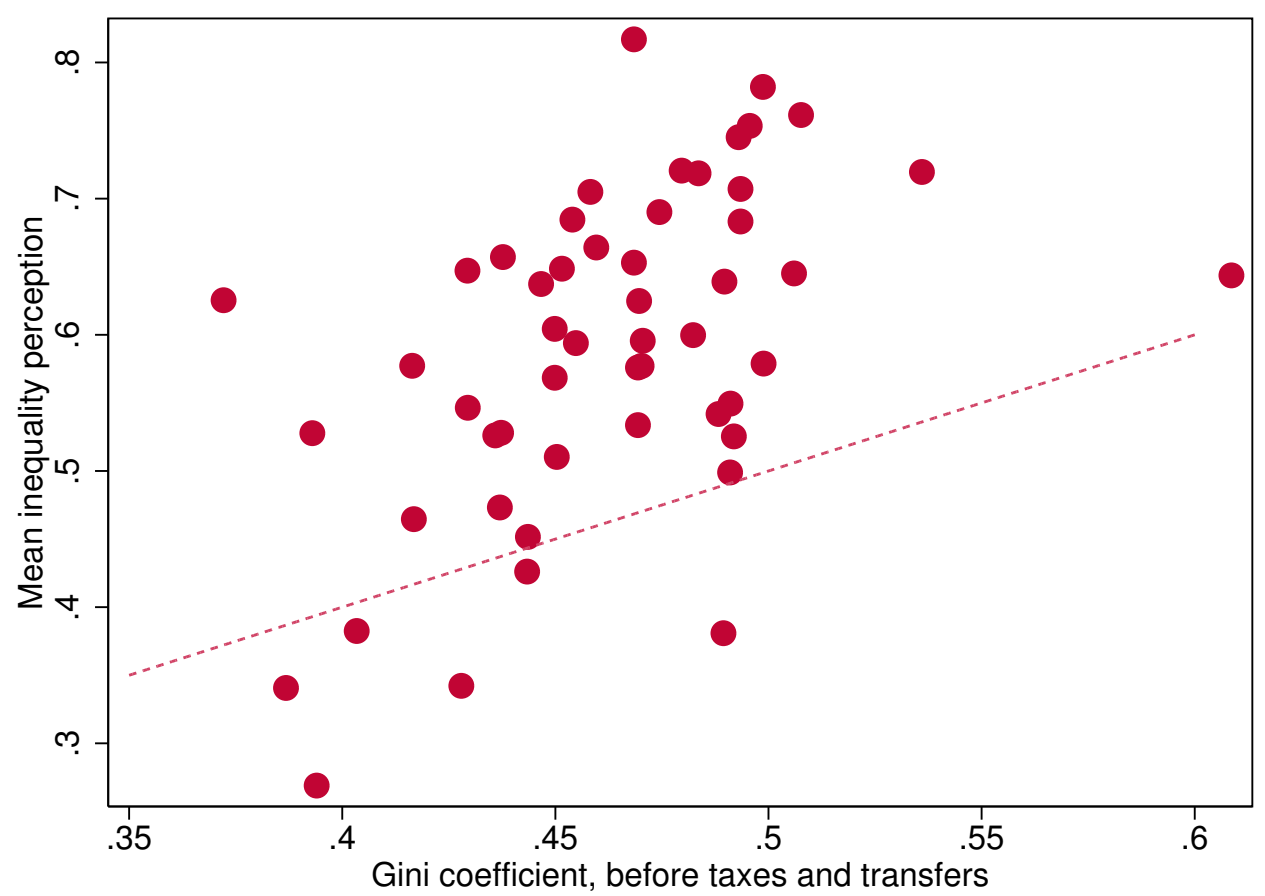

(a) Mean inequality perceptions versus Gini coefficient before taxes and transfers

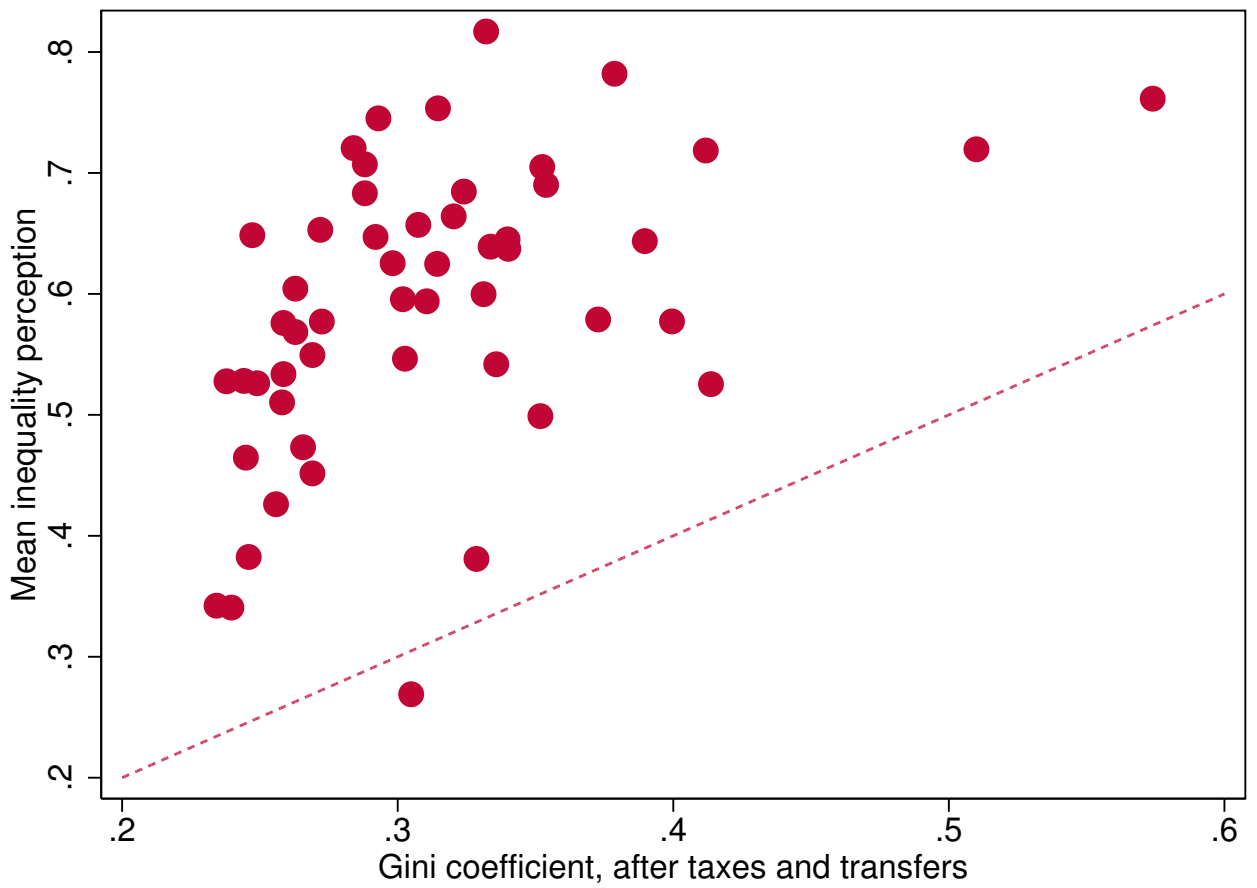

(b) Mean inequality perceptions versus Gini coefficient after taxes and transfers

Notes: Panel (a) shows mean inequality perceptions, by country $\times$ survey-year, against the corresponding Gini coefficient before taxes and transfer payments. Panel (b) plots mean inequality perceptions against the Gini coefficient after taxes and transfers. The dashed line shows the $45^{\circ}$-line. 
Figure 2: Mean subjective perceptions of the overall wage level and per-capita GDP at the country $\times$ survey-year level

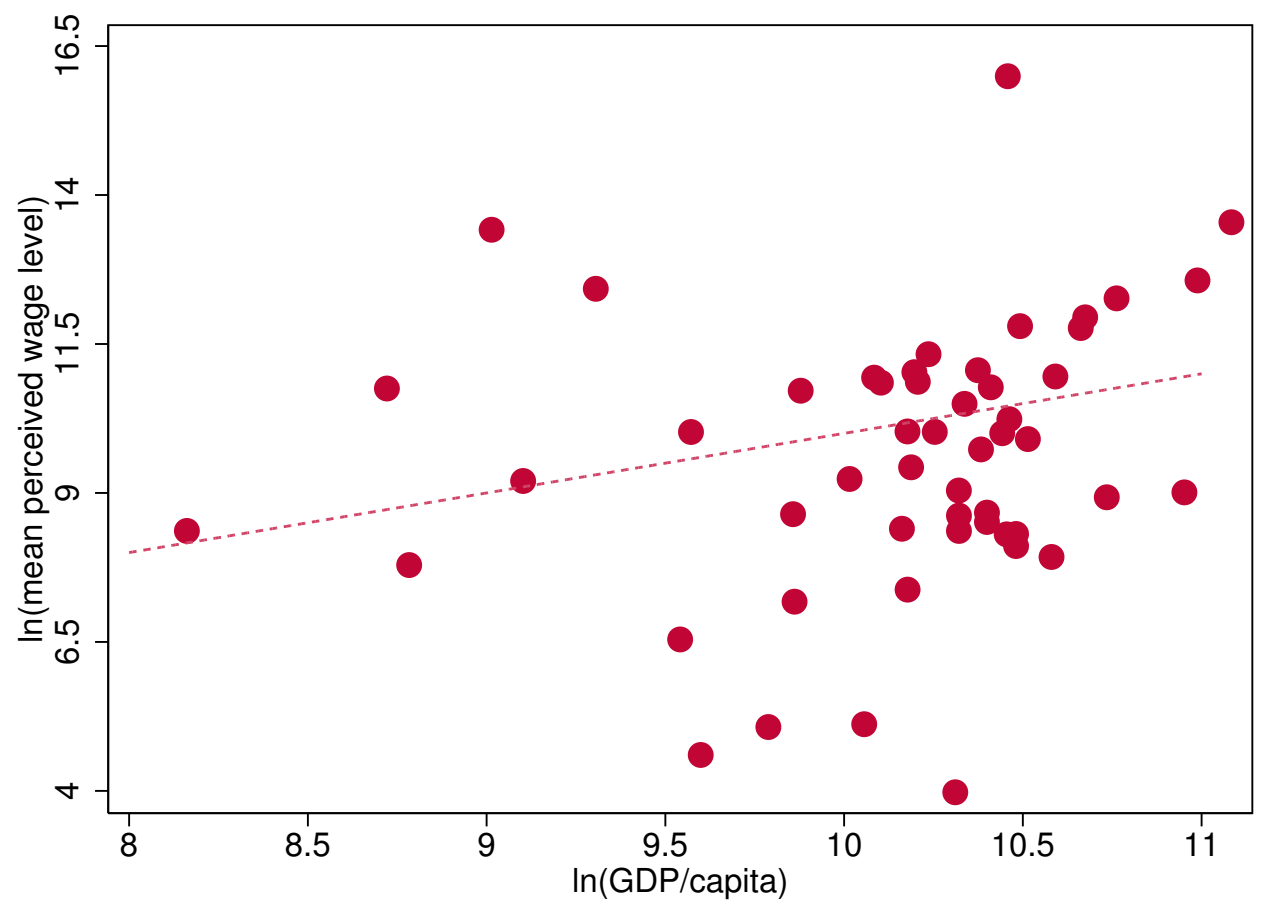

Notes: The figure plots the natural logarithm of mean perceptions of the overall wage level, computed according to equation (9) in the main text, in a given country and year against the natural logarithm of the corresponding per-capita GDP (in constant 2005 US dollars). The dashed line shows the $45^{\circ}$-line. 
Figure 3: Misperceptions of wage inequality

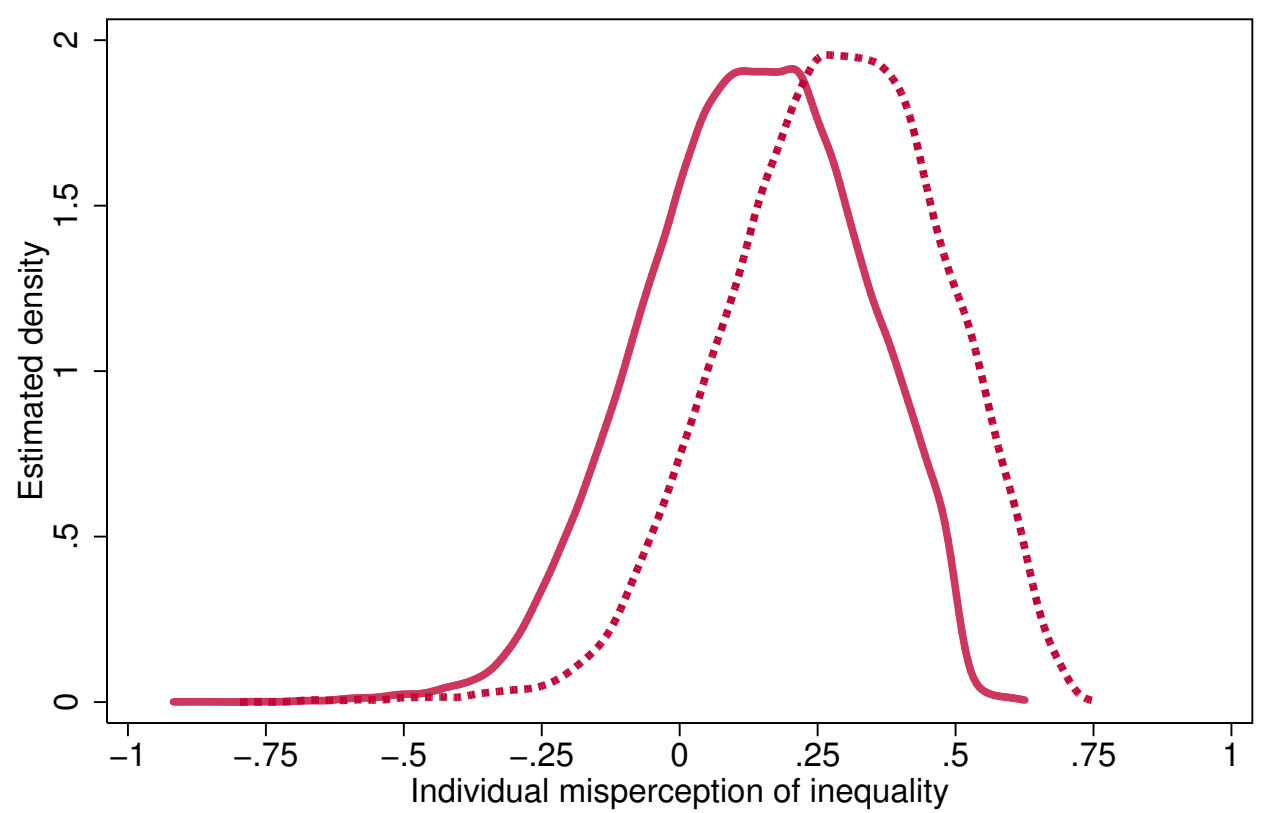

Deviation from Gini before ......... Deviation from Gini after

(a) Absolute deviations from the objective-level Gini coefficient in a given country $\times$ year

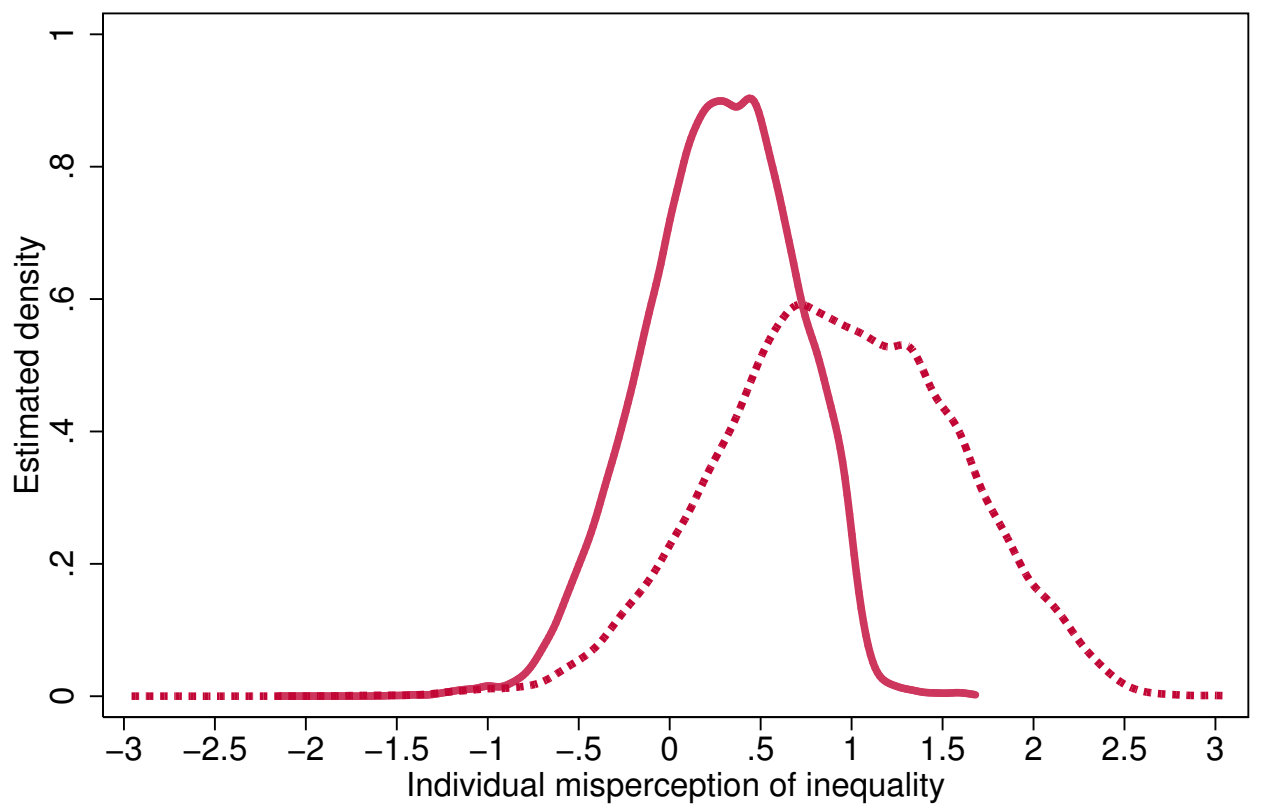

Deviation from Gini before .......... Deviation from Gini after

(b) Relative deviations from the objective-level Gini coefficient in a given country $\times$ year

Notes: The figure shows nonparametric density estimates (using the Gaussian kernel) of individual-level misperceptions of inequality as defined in equations (11a) and (11b) in the main text. 


\section{A Additional Tables and Figures}

Table A.1: Number of valid observations, by country and survey-year

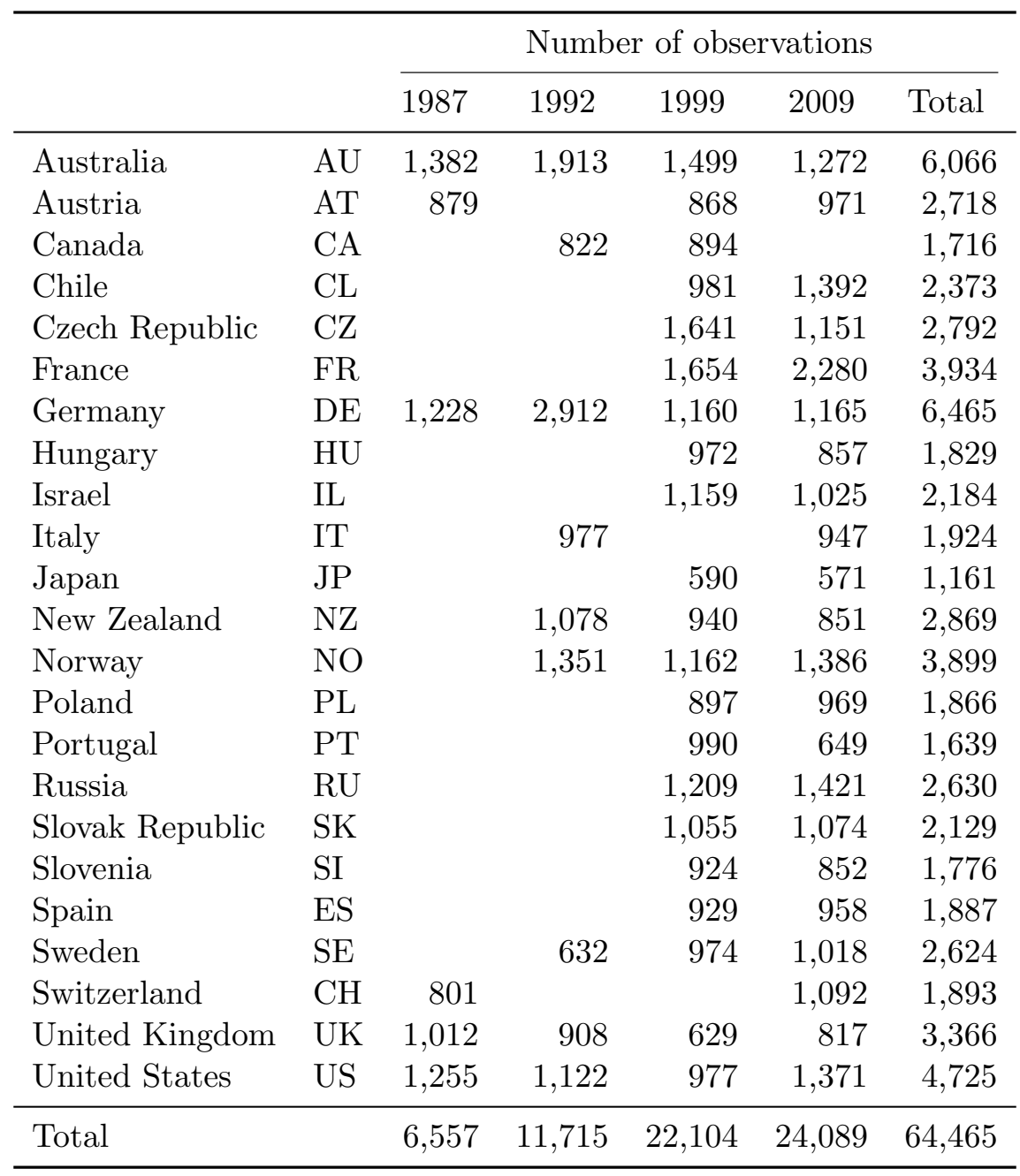

Notes: The table shows the number of individual observations in the final analysis sample (i.e. the sample used for the main estimates from table 2). 
Table A.2: Estimated country fixed-effects

\begin{tabular}{|c|c|c|c|}
\hline \multirow[b]{2}{*}{ Austria } & \multicolumn{3}{|c|}{ Inequality perception } \\
\hline & $\begin{array}{c}-0.049 \\
(0.035)\end{array}$ & $\begin{array}{c}-0.032 \\
(0.031)\end{array}$ & $\begin{array}{c}-0.032 \\
(0.031)\end{array}$ \\
\hline Canada & $\begin{array}{c}0.028 \\
(0.021)\end{array}$ & $\begin{array}{c}0.024 \\
(0.015)\end{array}$ & $\begin{array}{c}0.024 \\
(0.019)\end{array}$ \\
\hline Chile & $\begin{array}{c}0.033 \\
(0.024)\end{array}$ & $\begin{array}{r}-0.041 \\
(0.032)\end{array}$ & $\begin{array}{r}-0.042 \\
(0.036)\end{array}$ \\
\hline Czech Republic & $\begin{array}{r}-0.039 \\
(0.030)\end{array}$ & $\begin{array}{r}-0.019 \\
(0.029)\end{array}$ & $\begin{array}{r}-0.019 \\
(0.029)\end{array}$ \\
\hline France & $\begin{array}{l}0.054^{\star \star} \\
(0.023)\end{array}$ & $\begin{array}{l}0.066^{\star \star \star} \\
(0.019)\end{array}$ & $\begin{array}{l}0.066^{\star \star \star} \\
(0.019)\end{array}$ \\
\hline Hungary & $\begin{array}{c}0.035 \\
(0.022)\end{array}$ & $\begin{array}{l}0.045^{\star \star} \\
(0.017)\end{array}$ & $\begin{array}{l}0.045^{\star \star} \\
(0.017)\end{array}$ \\
\hline Israel & $\begin{array}{c}-0.058^{\star \star} \\
(0.022)\end{array}$ & $\begin{array}{c}-0.075^{\star \star \star} \\
(0.020)\end{array}$ & $\begin{array}{l}-0.075^{\star \star \star} \\
(0.021)\end{array}$ \\
\hline Italy & $\begin{array}{c}0.053 \\
(0.040)\end{array}$ & $\begin{array}{c}0.049 \\
(0.041)\end{array}$ & $\begin{array}{c}0.049 \\
(0.041)\end{array}$ \\
\hline Japan & $\begin{array}{c}-0.077^{\star \star} \\
(0.030)\end{array}$ & $\begin{array}{c}-0.091^{\star \star \star} \\
(0.026)\end{array}$ & $\begin{array}{c}-0.091^{\star \star \star} \\
(0.028)\end{array}$ \\
\hline New Zealand & $\begin{array}{r}-0.001 \\
(0.023)\end{array}$ & $\begin{array}{c}-0.009 \\
(0.021)\end{array}$ & $\begin{array}{c}-0.009 \\
(0.022)\end{array}$ \\
\hline Norway & $\begin{array}{l}-0.125^{\star \star \star} \\
(0.025)\end{array}$ & $\begin{array}{c}-0.115^{\star \star \star} \\
(0.015)\end{array}$ & $\begin{array}{c}-0.115^{\star \star \star} \\
(0.019)\end{array}$ \\
\hline Poland & $\begin{array}{c}0.016 \\
(0.026)\end{array}$ & $\begin{array}{c}0.016 \\
(0.023)\end{array}$ & $\begin{array}{c}0.016 \\
(0.022)\end{array}$ \\
\hline Portugal & $\begin{array}{r}-0.037^{\star} \\
(0.022)\end{array}$ & $\begin{array}{c}-0.062^{\star \star} \\
(0.026)\end{array}$ & $\begin{array}{c}-0.062^{\star \star} \\
(0.026)\end{array}$ \\
\hline Russia & $\begin{array}{l}0.086^{\star \star \star} \\
(0.029)\end{array}$ & $\begin{array}{c}0.013 \\
(0.028)\end{array}$ & $\begin{array}{c}0.013 \\
(0.037)\end{array}$ \\
\hline Slovak Republic & $\begin{array}{c}-0.041 \\
(0.044)\end{array}$ & $\begin{array}{c}-0.029 \\
(0.045)\end{array}$ & $\begin{array}{r}-0.029 \\
(0.045)\end{array}$ \\
\hline Slovenia & $\begin{array}{c}0.001 \\
(0.028)\end{array}$ & $\begin{array}{c}0.021 \\
(0.022)\end{array}$ & $\begin{array}{c}0.021 \\
(0.022)\end{array}$ \\
\hline Spain & $\begin{array}{l}-0.164^{\star \star \star} \\
(0.025)\end{array}$ & $\begin{array}{c}-0.176^{\star \star \star} \\
(0.022)\end{array}$ & $\begin{array}{c}-0.177^{\star \star \star} \\
(0.025)\end{array}$ \\
\hline Sweden & $\begin{array}{l}-0.154^{\star \star \star} \\
(0.028)\end{array}$ & $\begin{array}{c}-0.136^{\star \star \star} \\
(0.019)\end{array}$ & $\begin{array}{c}-0.136^{\star \star \star} \\
(0.020)\end{array}$ \\
\hline Switzerland & $\begin{array}{r}-0.001 \\
(0.030)\end{array}$ & $\begin{array}{r}-0.038^{\star} \\
(0.021)\end{array}$ & $\begin{array}{r}-0.038 \\
(0.035)\end{array}$ \\
\hline United States & $\begin{array}{l}0.046^{\star \star} \\
(0.022)\end{array}$ & $\begin{array}{c}0.025 \\
(0.020)\end{array}$ & $\begin{array}{c}0.025 \\
(0.022)\end{array}$ \\
\hline Germany-West & $\begin{array}{r}-0.014 \\
(0.023)\end{array}$ & $\begin{array}{c}0.002 \\
(0.018)\end{array}$ & $\begin{array}{c}0.002 \\
(0.017)\end{array}$ \\
\hline Germany-East & $\begin{array}{c}0.019 \\
(0.024)\end{array}$ & $\begin{array}{c}0.036^{\star} \\
(0.019)\end{array}$ & $\begin{array}{c}0.036^{\star} \\
(0.018)\end{array}$ \\
\hline Great Britain & $\begin{array}{c}0.009 \\
(0.022)\end{array}$ & $\begin{array}{c}0.003 \\
(0.020)\end{array}$ & $\begin{array}{c}0.004 \\
(0.020)\end{array}$ \\
\hline $\begin{array}{l}\text { Number of observations } \\
\text { R-Squared }\end{array}$ & $\begin{array}{l}64,465 \\
0.518\end{array}$ & $\begin{array}{l}64,465 \\
0.520\end{array}$ & $\begin{array}{l}64,465 \\
0.520\end{array}$ \\
\hline
\end{tabular}

Notes: ${ }^{\star},{ }^{\star \star},{ }^{\star \star \star}$ denotes statistical significance on the $10 \%, 5 \%$, and $1 \%$ level, respectively. Robust standard errors, clustered by country $\times$ year, are shown in parentheses. The table shows the estimated coefficients for the country dummies from the full specifications (i.e. columns 3, 6, and 9) of table 2. Australia is the reference country. 


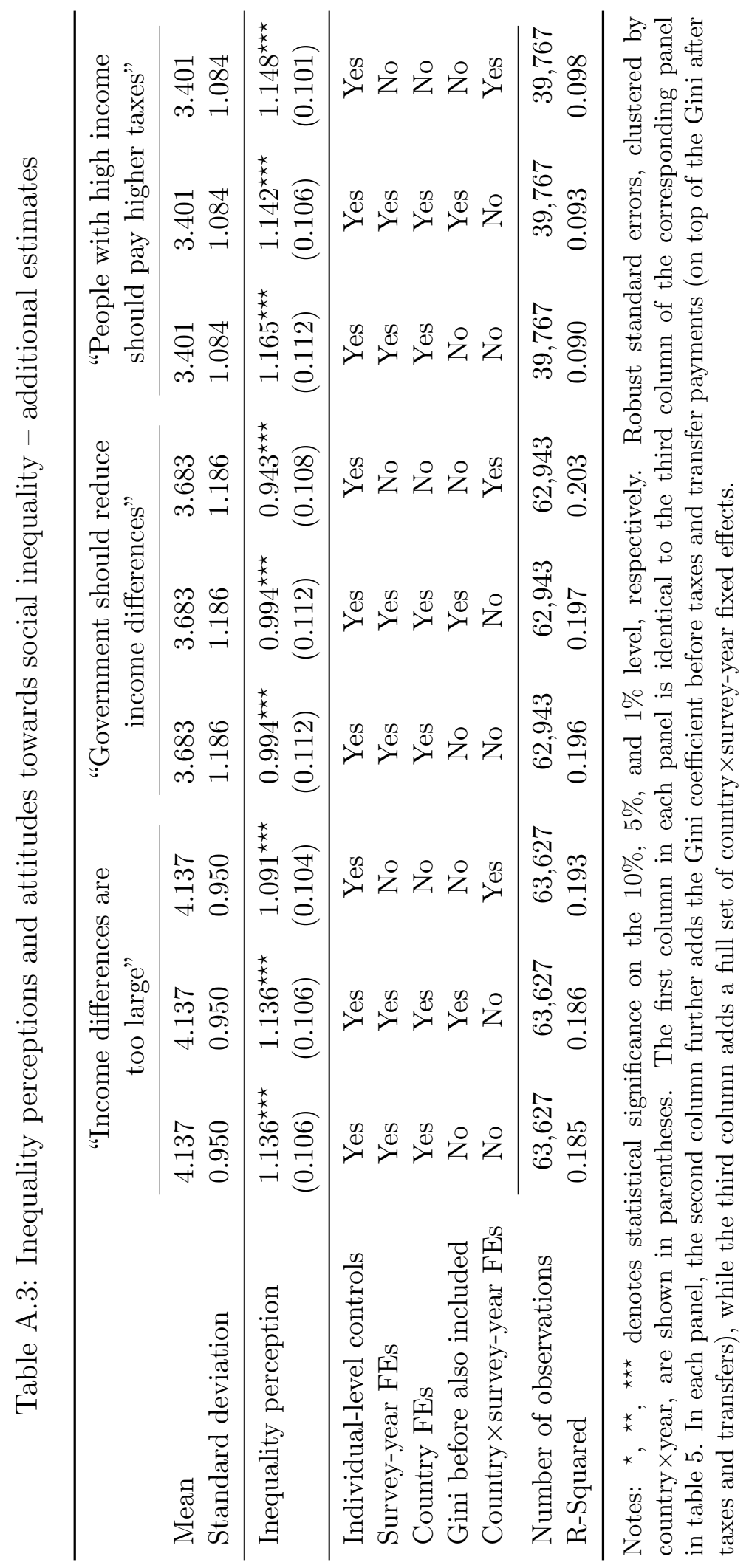




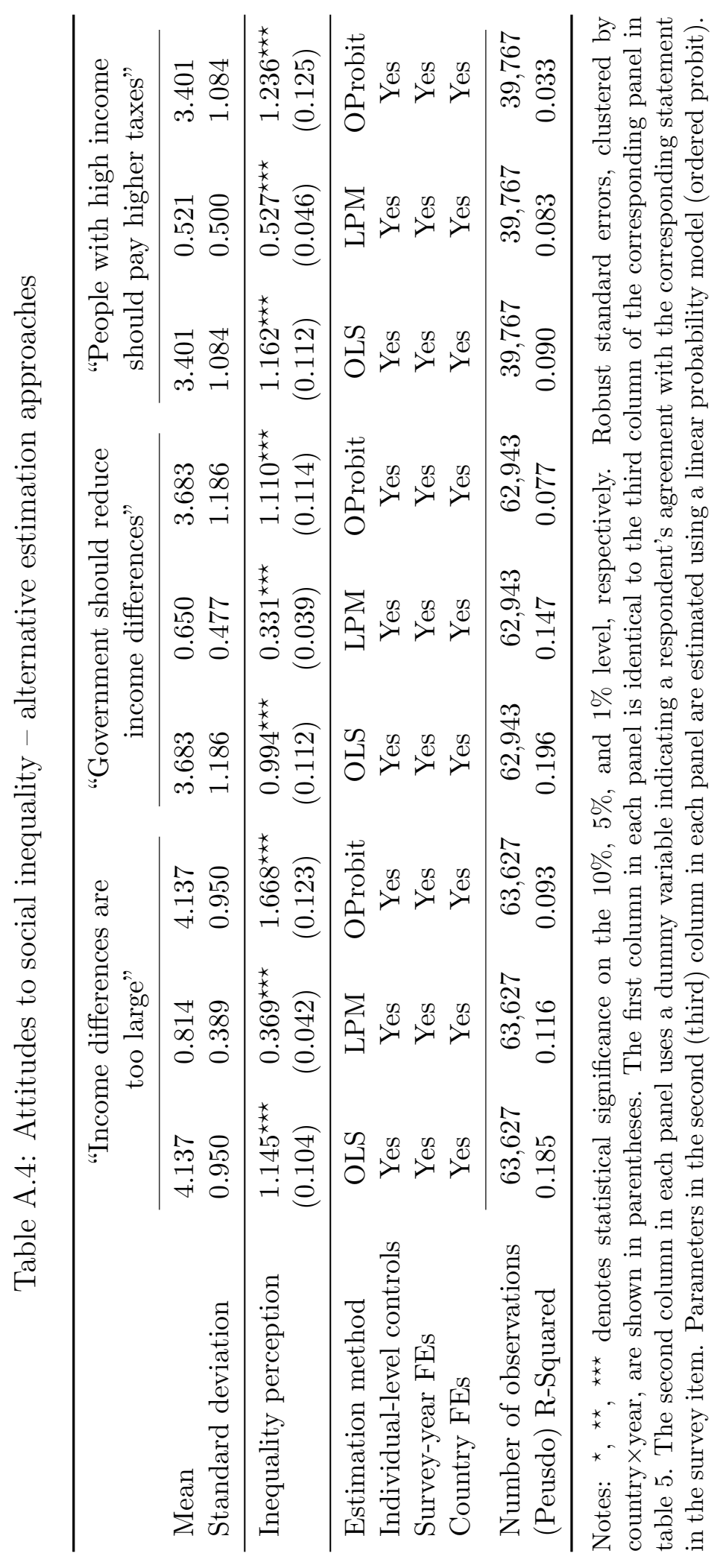




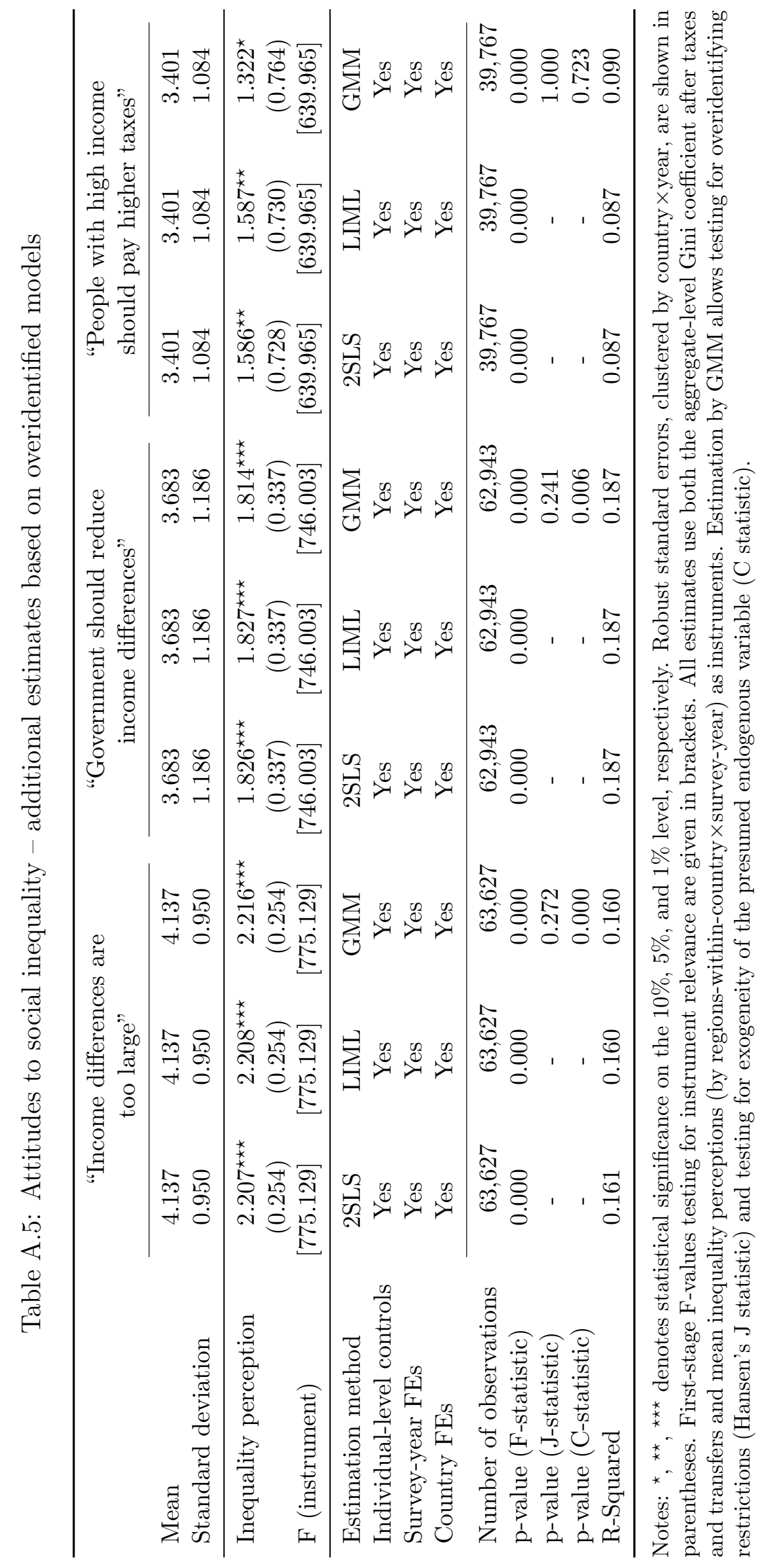


Figure A.1: Misperceptions of wage inequality; using alternative constructions of inequality perceptions

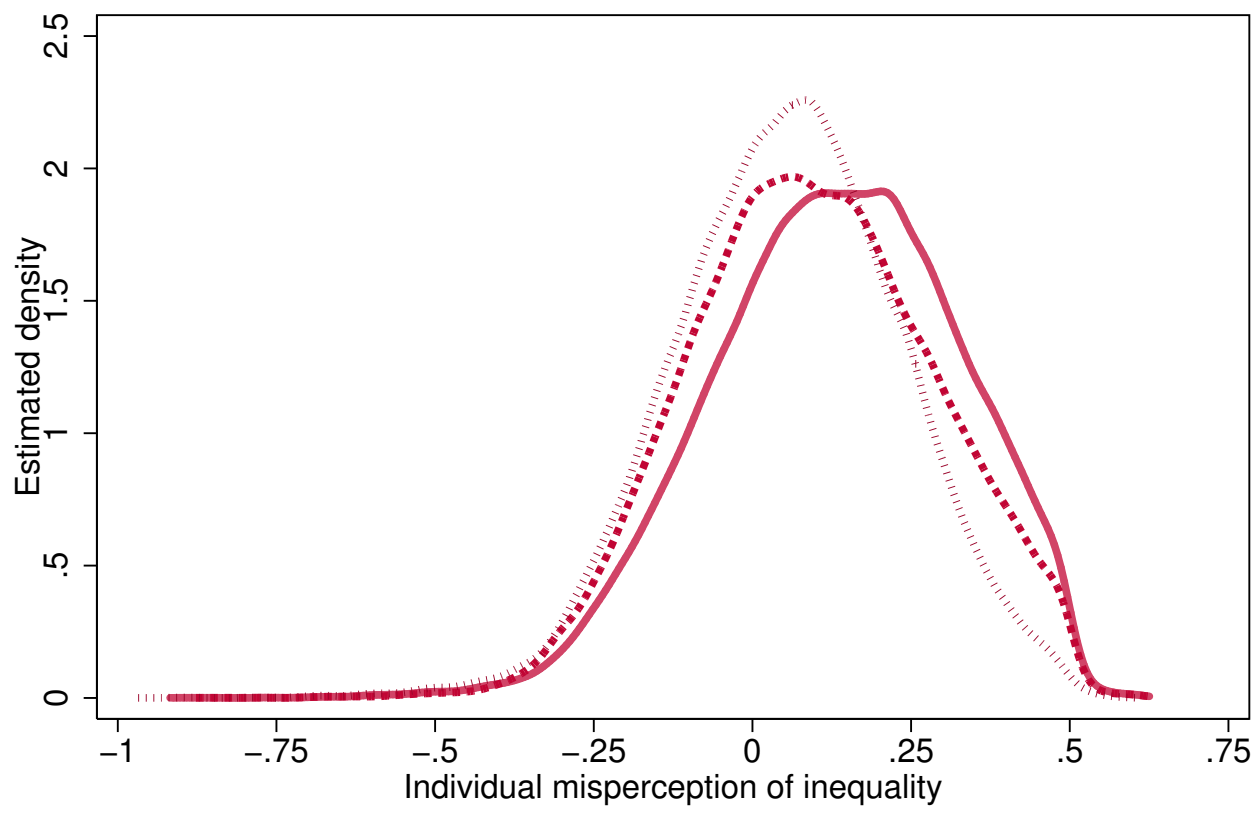

Baseline ........ All occupations …n...... Excluding executives

Notes: Notes: The figure shows nonparametric density estimates (using the Gaussian kernel) of individual-level misperceptions of inequality. The figure compares individual-level misperceptions of wage inequality using three alternative constructions of inequality perceptions (using different sets of occupational wage estimates). In the "baseline" version, only those four occupations appearing in all waves of the survey are used; the two alternative constructions use either all available occupations ("All occupations") or the baseline set of occupations less executives ("Excluding executives"). 